\title{
Cell Death Mediated by the N-Terminal Domains of a Unique and Highly Conserved Class of NB-LRR Protein
}

\author{
Sarah M. Collier, ${ }^{1,2}$ Louis-Philippe Hamel, ${ }^{3}$ and Peter Moffett ${ }^{1,3}$ \\ ${ }^{1}$ Boyce Thompson Institute for Plant Research, Cornell University, Ithaca, NY 14853 U.S.A.; ${ }^{2}$ Department of Plant Breeding \\ \& Genetics, Cornell University, Ithaca, NY 14853 USA; ${ }^{3}$ Centre de Recherche en Amélioration Végétale, Département de \\ Biologie, Université de Sherbrooke, Sherbrooke, QC, J1K 2R1 Canada
}

Submitted 1 March 2011. Accepted 11 April 2011.

\begin{abstract}
Plant genomes encode large numbers of nucleotide-binding, leucine-rich repeat (NB-LRR) proteins, many of which are active in pathogen detection and defense response induction. NB-LRR proteins fall into two broad classes: those with a Toll and interleukin-1 receptor (TIR) domain at their N-terminus and those with a coiled-coil $(\mathrm{CC})$ domain at the N-terminus. Within CC-NB-LRR-encoding genes, one basal clade is distinguished by having $\mathrm{CC}$ domains resembling the Arabidopsis thaliana RPW8 protein, which we refer to as $\mathrm{CC}_{\mathrm{R}}$ domains. Here, we show that $C_{R}$-NB-LRR-encoding genes are present in the genomes of all higher plants surveyed, and that they comprise two distinct subgroups: one typified by the Nicotiana benthamiana N-required gene 1 (NRG1) protein and the other typified by the Arabidopsis activated disease resistance gene 1 (ADR1) protein. We further report that, in contrast to CC-NB-LRR proteins, the $C_{R}$ domains of both NRG1and ADR1-like proteins are sufficient for the induction of defense responses, and that this activity appears to be SGT1-independent. Additionally, we report the apparent absence of both NRG1 homologs and TIR-NB-LRR-encoding genes from the dicot Aquilegia coerulea and the dicotyledonous order Lamiales as well as from monocotyledonous species. This strong correlation in occurrence is suggestive of a functional relationship between these two classes of NB-LRR proteins.
\end{abstract}

To defend themselves against pathogens, plants possess a sophisticated multilevel immune system. At a basal level, plant pattern recognition receptors are able to detect conserved pathogen-associated molecular patterns (PAMPs) and initiate a lowimpact resistance responses known as PAMP-triggered immunity (PTI), which involves mitogen-activated protein kinase signaling, callose deposition, and production of reactive oxygen species (Chisholm et al. 2006). Should a pathogen overcome or circumvent this line of defense, it may yet be intercepted by a second resistance mechanism termed effector-triggered immunity (ETI) or gene-for-gene resistance (Flor 1971), in which the protein products of plant resistance $(R)$ genes specifically recognize cognate pathogen avirulence $(A v r)$ gene products and trigger a stronger resistance response. The majority of $R$ genes

Corresponding author: P. Moffett; E-mail: peter.moffett@usherbrooke.ca

*The $\boldsymbol{e}$-Xtra logo stands for "electronic extra" and indicates that three supplementary figures and two supplementary tables are published online. encode nucleotide-binding leucine-rich repeat (NB-LRR) proteins, which are defined by the presence of a central NB domain and a C-terminal LRR domain. Located between the NB and LRR lies a region known as the Apaf-1, R proteins, and CED4 homology (ARC) domain which, together with the NB, constitutes a nucleotide-binding pocket bearing homology to members of the signal transduction ATPases with numerous domains class of ATPases (Leipe et al. 2004; Tameling et al. 2002). Although both the NB and ARC domains possess numerous conserved, functionally critical motifs, the LRR is more variable - an attribute which facilitates its role in determining recognition specificity (Collier and Moffett 2009).

Over 70 NB-LRR proteins of known specificity have been cloned (Sacco and Moffett 2009), and thousands more NBLRR-encoding sequences are listed in GenBank (available online from the National Center for Biotechnology Information). Analysis of conserved NB-ARC sequences reveals two major classes within NB-LRR proteins (Meyers et al. 1999), a division also supported by their N-terminal structures. Most members of the first class possess a domain homologous to Toll and interleukin-1 receptors (TIR) at their N-terminus, whereas much greater variability exists among $\mathrm{N}$-terminal domains of the second class. Because many of these variable $\mathrm{N}$ terminal regions are predicted to form coiled-coil (CC) structures, members of this class are collectively referred to as $\mathrm{CC}$ NB-LRR proteins. However, the CC domain is sometimes joined or replaced by additional structures, such as predicted BED DNA-binding and Solanaceae domains (Collier and Moffett 2009). Despite an overall lack of sequence similarity, essentially all characterized canonical CC domains-whether joined by additional domains or not-possess a small "EDVID" motif (Rairdan et al. 2008) and are thus described as belonging to the $\mathrm{CC}_{\mathrm{EDVID}}$ subclass (Collier and Moffett 2009). A less abundant subclass of $\mathrm{CC}$ domain also exists, previously termed $\mathrm{CC}_{\mathrm{RPW} 8}$ (Collier and Moffett 2009), in which no EDVID motif is present and which bears closest sequence similarity to RPW8, a non-NB-LRR R protein from Arabidopsis thaliana that confers broad-spectrum resistance against powdery mildew (Erysiphe spp.) (Xiao et al. 2001). Interestingly, NB-LRR proteins that possess an RPW8-like CC domain (hereafter referred to as $C_{R}$ ) are also found to form a distinct subclass within the CC-NB-LRR proteins based on their NB-ARC sequence. This $C_{R}-N B-L R R$ subclass has variously been referred to as non-TIR N4 and CNL-A, and appears to be one of the most ancestral of major CC-NB-LRR clades (Cannon et al. 2002; McHale et al. 2006; Meyers et al. 2003). Few $C_{R_{R}}-N B-$ LRR proteins have been cloned or functionally characterized 
to date, although they have been reported to possess characteristic motifs that distinguish them from other NB-LRR proteins (Chini and Loake 2005). The best-studied members of this group include N-required gene 1 (NRG1) of Nicotiana benthamiana and activated disease resistance gene 1 (ADR1) of $A$. thaliana. NbNRG1 was identified through a gene-silencing screen as being required for the function of the tobacco $(N$. glutinosa) TIR-NB-LRR protein N, apparently acting downstream of effector recognition by $\mathrm{N}$ (Peart et al. 2005). ADR1 was identified in an activation-tagging screen, where it was observed that ADR1 overexpression leads to constitutive defense activation as well as drought tolerance (Chini et al. 2004; Grant et al. 2003). It is interesting to note that neither NRG1 nor ADR1 have been reported to act in the classical gene-for-gene manner of canonical $\mathrm{R}$ proteins, perhaps suggesting that $\mathrm{CC}_{\mathrm{R}}$-NB-LRR proteins function somewhat differently than the more common $\mathrm{CC}_{\mathrm{EDVID}}-\mathrm{NB}-\mathrm{LRR}$ proteins.

Although the expansion of NB-LRR-encoding genes has been remarkably prolific, with most plant genomes containing several hundred family members (Sacco and Moffett 2009), they also exhibit great plasticity. Orthologous relationships can be difficult to determine due to the gene duplication, loss, recombination, or rapid diversification frequently observed within many NB-LRR lineages, and the relative abundance of various lineages may also vary greatly between different species (McDowell and Simon 2006; McHale et al. 2006; Velasco et al. 2010). In an extreme example, TIR-NB-LRR-encoding genes are completely absent from all monocot genomes thus far queried (Bai et al. 2002; Meyers et al. 1999; Pan et al. 2000; Tarr and Alexander 2009). In contrast, genes encoding $\mathrm{CC}_{\mathrm{R}}$-NB-LRR proteins constitute a relatively conservative clade: they have been identified in numerous monocot and dicot species, as well as in gymnosperms, and there is currently no indication that this gene family has expanded disproportionately in any plant lineage (this report). Certain $\mathrm{CC}_{\mathrm{R}}-\mathrm{NB}$ LRR-encoding genes, including certain Arabidopsis homologs, have been found to display particularly low levels of sequence variation both within and between species (Bakker et al. 2006; Grant et al. 2003; Jermstad et al. 2006). Furthermore, in sharp contrast to typical NB-LRR proteins, the LRR domains of ADR 1 and its three paralogs ( $A D R 1-L 1,-L 2$, and $-L 3)$ display higher levels of sequence conservation than do their corresponding NB-ARC domains (Chini and Loake 2005). Taken together, these observations would seem to suggest that $C_{R^{-}}$ NB-LRR proteins might play a role that is both conserved and unique among NB-LRR proteins.

NB-LRR proteins are collectively able to recognize a broad array of Avr proteins and, while the pathogens recognized are diverse, the response initiated upon NB-LRR activation is remarkably homogenous. NB-LRR-mediated resistance shares many components of basal resistance (Jones and Dangl 2006) but it is often also accompanied by programmed cell death at the site of infection, termed the hypersensitive response (HR). Additionally, the efficacy of NB-LRR-mediated resistance is not restricted to the class of pathogen initially recognized but can extend across kingdoms (Rentel et al. 2008; Sohn et al. 2007; Tobias et al. 1999). While specific pathogen detection is thought to result from the combined action of the LRR and Nterminal domains, the origin of NB-LRR signal initiation remains unclear. Several TIR domains, including those of RPS4, RPP1, and L10 (Frost et al. 2004; Krasileva et al. 2010; Swiderski et al. 2009), have been shown to be sufficient for inducing defense responses upon overexpression but no TIRinteracting signaling proteins have been identified. To date, a similar activity has not been demonstrated for any isolated $\mathrm{CC}$ domain. Rather, the NB domain of the potato (Solanum tuberosum) Rx CC-NB-LRR protein was found to be sufficient to induce defense responses (Rairdan et al. 2008). Whether this behavior extends to other CC-NB-LRR proteins remains to be determined.

On investigating the potential for signaling capacity of the $\mathrm{CC}$ domains of various characterized solanaceous NB-LRR proteins, we find that only the $\mathrm{CC}_{\mathrm{R}}$ domain of NRG1 is capable of independently inducing defense responses. We also demonstrate that $\mathrm{CC}_{\mathrm{R}}$-mediated resistance signaling is common to both NRG1- and ADR1-like proteins of solanaceous species and $A$. thaliana, and that this function does not appear to depend on SGT1. We further demonstrate that NRG1- and ADR1-like proteins are involved in the resistance response mediated by a canonical CC-NB-LRR protein. Additionally, we report that NRG1 and ADR1 represent two distinct subclades of $C_{R}-N B-L R R$ proteins, and that these lineages show a degree of conservation and retention through speciation not seen with genes encoding other classes of NB-LRR proteins. Curiously, we note that, although $A D R l$-like genes are present in every higher plant genome investigated, the occurrence of NRG1 family members mirrors that of TIR-NB-LRR-encoding genes, suggesting an evolutionary and functional relationship between these proteins.

\section{RESULTS}

\section{NRG1 $\mathrm{CC}_{\mathbf{R}}$-mediated HR induction.}

To better understand whether the lack of demonstrated CCmediated HR is indicative of contrasting modes of signaling by TIR-NB-LRR versus CC-NB-LRR proteins, we examined the CC domains of a number of solanaceous CC-NB-LRR proteins, including NRG1. We transiently expressed, by agroinfiltration, $17 \mathrm{CC}$ domains derived from solanaceous NB-LRR proteins, 14 of which had not previously been so tested. A representative experiment, including the $\mathrm{CC}$ domains of I2, R3a, $\mathrm{RB}, \mathrm{Bs} 2$, and Rx, is shown in Figure 1. None of these CC domains induced an HR in tobacco ( $N$. tabacum) leaves, in contrast to the N-terminus of NRG1, which induced a strong HR, visible after $24 \mathrm{~h}$ (Fig. 1A).

Because the N-terminal region of $\mathrm{CC}_{\mathrm{R}}-\mathrm{NB}-\mathrm{LRR}$ proteins cannot be aligned with those of $\mathrm{CC}_{\mathrm{EDVID}}-\mathrm{NB}-\mathrm{LRR}$ sequences, we initially used an NRG1 clone encompassing the first 225 amino acids, terminating just before the P-loop motif of the $\mathrm{NB}$ domain. While ensuring inclusion of the entire $\mathrm{CC}_{\mathrm{R}}$ domain, this clone also contained the extreme $\mathrm{N}$-terminal portion of the NB domain. To better delineate the region involved in signal initiation, we performed a deletion analysis of the NRG1 N terminus (Fig. 1B). We constructed a clone terminating just before the NB domain (1 to 182), as well as $\mathrm{N}$ - and $\mathrm{C}$ terminal truncations within the $\mathrm{CC}_{\mathrm{R}}$ domain. Among these was a deletion of amino acids 1 to 13 which, in RPW8, are thought to be part of a transmembrane or targeting motif (Xiao et al 2001). Although removal of NB remnants had no effect on $H R$ induction, all deletions within the $\mathrm{CC}_{\mathrm{R}}$ domain failed to produce HR upon transient expression (Fig. 1C). In the cases of NRG (1 to 147 ) and (13 to 147), lack of activity could be due to compromised stability, because protein accumulation for these two variants was somewhat less than that of active versions. NRG1 (13 to 225), however, showed high levels of protein accumulation and yet was unable to induce HR (Fig. 1C). Therefore, we conclude that the entire $C_{R}$ domain is necessary and sufficient to induce an HR, and that amino acids 1 to 13 are likely critical for this function.

NRG1 and ADR1 describe distinct $\mathrm{CC}_{\mathrm{R}}$-NB-LRR subclades.

$A D R l$ is among Arabidopsis genes showing highest sequence similarity to NRG1. Therefore, we undertook a more extensive phylogenetic analysis of $\mathrm{CC}_{\mathrm{R}}-\mathrm{NB}-\mathrm{LRR}$-encoding genes to de- 
termine the distribution and complexity of this lineage. This was accomplished by a thorough search of fully sequenced genomes, aiming not to identify every $\mathrm{CC}_{\mathrm{R}}$-NB-LRR-encoding sequence or sequence fragment currently available but rather with the specific purpose of ascertaining the distribution patterns of $\mathrm{CC}_{\mathrm{R}}$-NB-LRR-encoding genes through examination of this limited but largely complete data set. $C_{R}$-NB-LRR-encoding genes were identified by protein-protein BLAST (BLASTP) against the predicted proteomes of all 22 plants with sequenced and annotated genomes contained in the Phytozome database (available online from the DOE Joint Genome Institute and UC Berkley Center for Integrative Genomics). AtADR1 was used as a query, and sequences from each proteome were compiled down through the first non- $\mathrm{CC}_{\mathrm{R}}-\mathrm{NB}$ LRR hit returned (determined by bit-score cutoff and subsequent phylogenetic confirmation), thus ensuring a reasonably complete representation of each genome's $C C_{R^{-}} N B-L R R$ com- plement (Supplementary Table $\mathrm{S} 1$ ). Although no $C C_{R^{-}} N B-L R R$ sequences were readily identifiable in Volvox, Chlamydomonas, Physcomitrella, or Selaginella spp., every higher plant surveyed contained at least one $\mathrm{CC}_{\mathrm{R}}$-NB-LRR-encoding gene.

Full-length $\mathrm{CC}_{\mathrm{R}}$-NB-LRR amino acid sequences were aligned by ClustalW. Phylogeny construction based on the NB-ARC region revealed two distinct, strongly supported clades, one containing NRG1 and the other containing ADR1 (Fig. 2). Similar groupings were obtained from trees based on the LRR and $\mathrm{CC}_{\mathrm{R}}$ domains, as well as from full-length sequences (Supplementary Fig. S1). Because some species contained multiple homologs per clade, we limited our final analysis in Figure 2 to a single representative per clade per species, except in the case of gymnosperm sequences (discussed below). Arabidopsis lyrata sequences were also excluded from analysis because of excessive redundancy with $A$. thaliana. One striking observation from this analysis is that, with few exceptions, every flow-
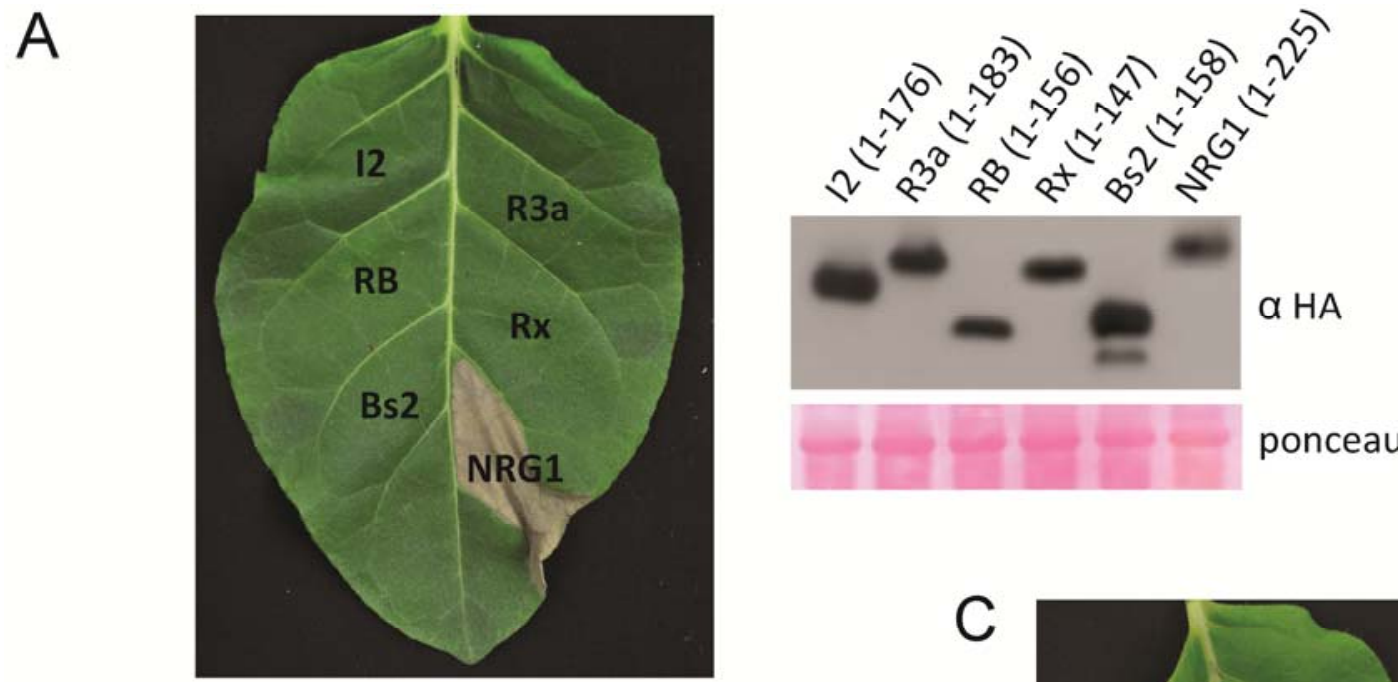

B

NRG1
$(850$ aa)
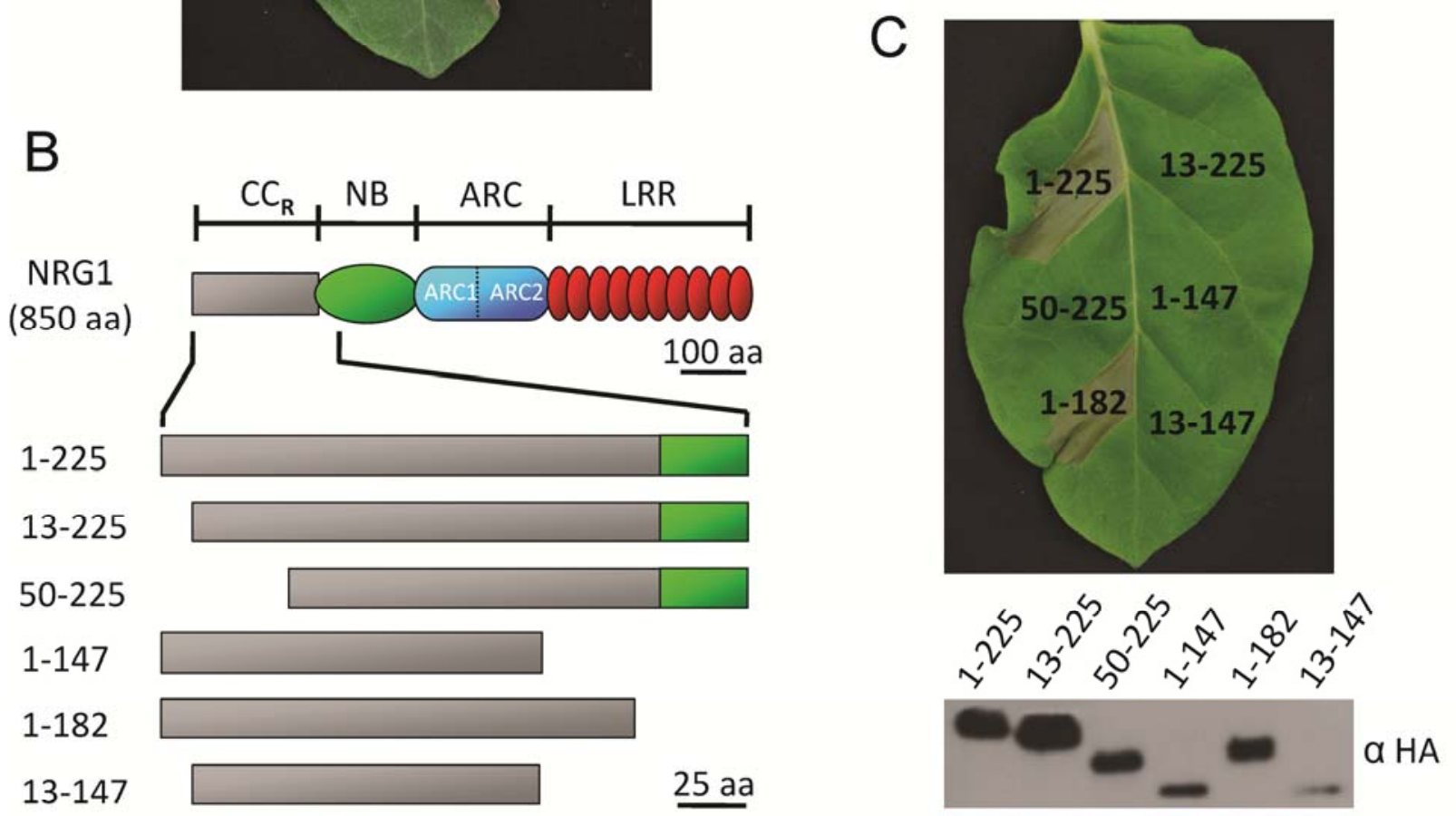

13-147

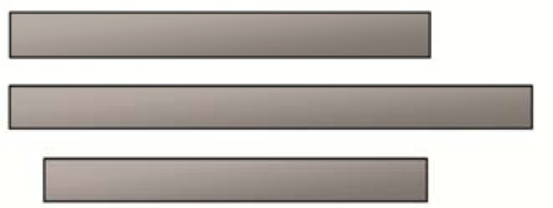

$\underline{25}$ aa

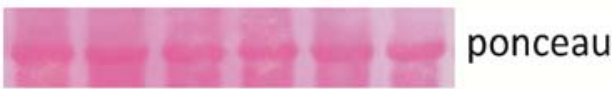

Fig. 1. NRG1 coiled-coil domain resembling the Arabidopsis thaliana RPW8 protein $\left(\mathrm{CC}_{\mathrm{R}}\right)$-mediated hypersensitive response (HR) induction. A, Transient expression of representative CC domains in Nicotiana tabacum. Leaves were agroinfiltrated with CC domains of I2, R3a, RB, Rx, Bs2, and NRG1 as indicated and photographed 3 days later. Proteins extracts from agroinfiltrated patches were subjected to anti-hemagglutinin (HA) immunoblotting after $48 \mathrm{~h}(24 \mathrm{~h}$ for NRG1) (right panel). B, Schematic of NRG1 N-terminus truncations. NB = nucleotide binding, ARC = Apaf-1, R proteins, and CED4 homology, LRR = leucine-rich repeat. $\mathbf{C}$, HR induction after agroinfiltration of indicated NRG1 derivatives (top panel) and anti-HA immunoblotting of protein extracts prepared $24 \mathrm{~h}$ after agroinfiltration (bottom panel). 
ering plant queried encodes both ADR1-like and NRG1-like proteins (Fig. 2).

Although no fully sequenced gymnosperm genomes are currently available, we were interested in examining members of this lineage as well. Therefore, we performed a BLASTP search of the GenBank Coniferophyta protein collection with full-length AtADR1 as a query, obtaining five complete or nearly complete $\mathrm{CC}_{\mathrm{R}}$-NB-LRR sequences (Fig. 2). One of

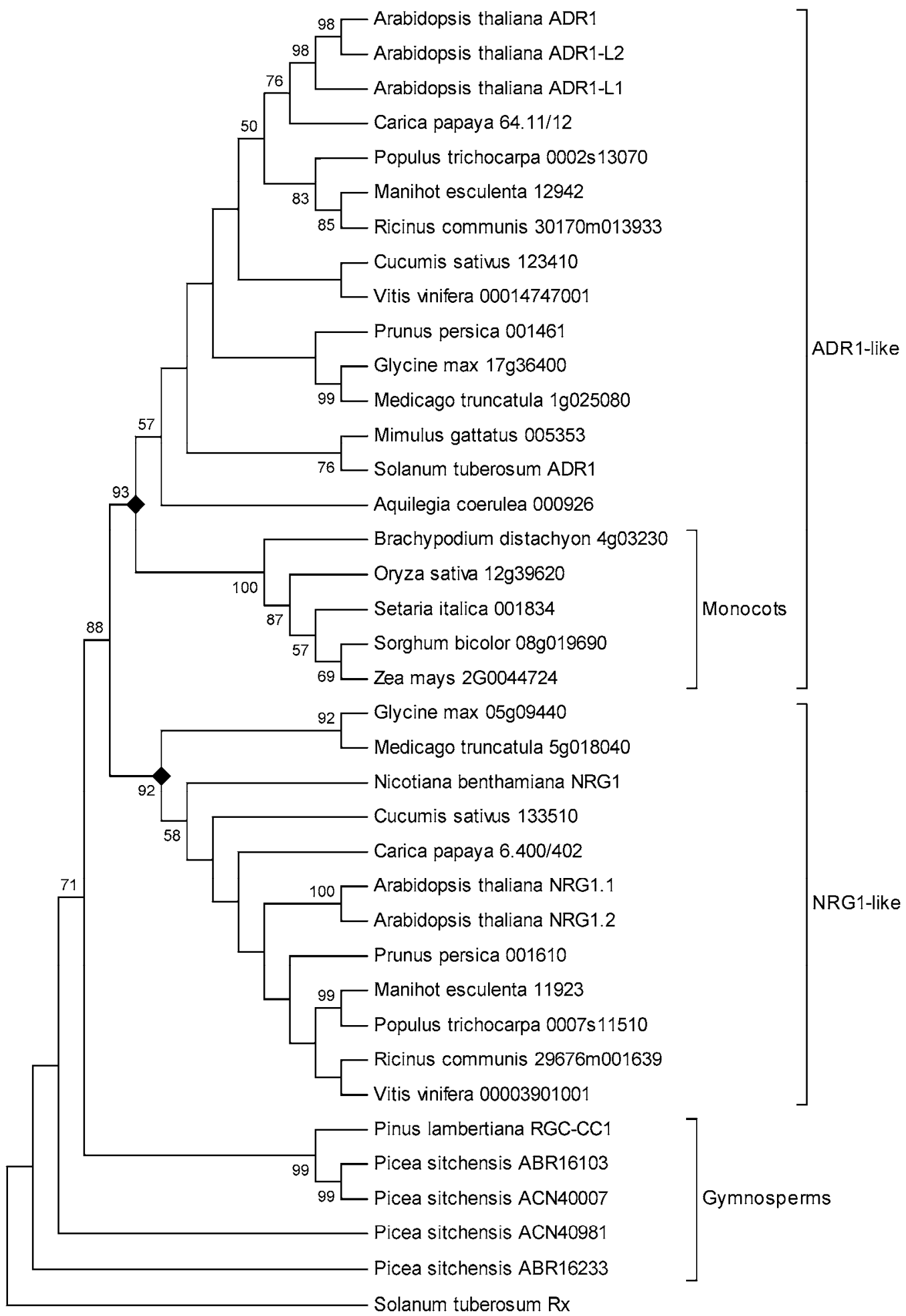

Fig. 2. Phylogenetic analysis of coiled-coil domain resembling the Arabidopsis thaliana RPW8 protein $\left(\mathrm{CC}_{\mathrm{R}}\right)$ nucleotide-binding, leucine-rich repeat (NBLRR) proteins. Bootstrap consensus tree constructed using the neighbor-joining method from the aligned NB Apaf-1, R proteins, and CED4 homology (ARC) domains of NRG1-like and ADR1-like predicted amino acid sequences from plant species with fully sequenced genomes. Additional CC $\mathrm{R}_{\mathrm{R}} \mathrm{NB}-\mathrm{LRR}$ proteins used elsewhere in this study as well as available gymnosperm sequences are also included. For species with multiple NRG1 or ADR1 homologs, a single full-length sequence was selected at random as a representative for each group. In all, 1,000 replicate trees were analyzed, and resultant bootstrap percentage values above 50 are shown at branch nodes. Putative proteins are labeled by genus, species, and $(\alpha)$ numerical identifier. Black diamonds demark strongly supported NRG1-like and ADR1-like clades (also indicated by brackets), and the location of monocot- and gymnosperm-derived sequences are indicated by brackets. The tree is rooted with Rx. 
these (Pinus lambertiana $\mathrm{RGC}-\mathrm{CC} 1$ ) has been previously studied and found to possess remarkably low levels of sequence variation between unrelated individuals (Jermstad et al. 2006). Although the five gymnosperm proteins all group as being most similar to one another, the limited number of sequences available were insufficient to determine whether conifers indeed possess just a single class of $\mathrm{CC}_{\mathrm{R}}$-NB-LRR protein or whether, due to chance, sequences from only one of two clades had been recovered. In order to resolve this uncertainty, we also performed a search of conifer expressed sequence tags (EST) in the GenBank collection. To ensure representation of both ADR1-like and NRG1-like sequences, if present, we used the NB-ARC domains of AtADR1, NbNRG1, Rx, and N (the latter two as representative CC-NB-LRR and TIR-NB-LRR proteins, respectively) as queries, and compiled the top 10 hits from each search. Although searches with $\mathrm{Rx}$ and $\mathrm{N}$ each returned 10 unique hits, hits from ADR1- and NRG1-based searches were somewhat overlapping. Phylogenetic analysis of the resulting sequences confirmed that, while conifer $\mathrm{CC}_{\mathrm{R}}-\mathrm{NB}$ LRR-encoding sequences are clearly distinct from TIR-NBLRR and canonical CC-NB-LRR sequences, grouping most closely with angiosperm-derived $\mathrm{CC}_{\mathrm{R}}$-NB-LRR sequences, they form their own subclade without clear membership to either the ADR1 or NRG1 group (Supplementary Fig. S2). Therefore, we can be reasonably confident that conifers possess only a single class of $\mathrm{CC}_{\mathrm{R}}-\mathrm{NB}-\mathrm{LRR}$ protein, and that the five fulllength sequences obtained provide a fair representation. Al-

Table 1. Results of Lamiales and Aquilegia coerulea BLAST searches

\begin{tabular}{|c|c|c|c|}
\hline Query & Species & Identifier $^{\mathrm{a}}$ & Group $^{b}$ \\
\hline \multicolumn{4}{|l|}{ Lamiales } \\
\hline $\mathrm{N}$ & Mimulus guttatus & GR052998 & ADR1 \\
\hline $\mathrm{N}$ & Antirrhinum majus & AJ568282 & ADR1 \\
\hline $\mathrm{N}$ & Triphysaria pusilla & EY157110 & ADR1 \\
\hline $\mathrm{N}$ & M. guttatus var. nastus & GO954238 & $\mathrm{CC}$ \\
\hline $\mathrm{N}$ & Striga hermonthica & FS493128 & $\mathrm{CC}$ \\
\hline $\mathrm{N}$ & M. lewisii & GR192604 & $\mathrm{CC}$ \\
\hline $\mathrm{Rx}$ & M. guttatus var. nastus & GO954238 & $\mathrm{CC}$ \\
\hline $\mathrm{Rx}$ & M. guttatus & GR152322 & $\mathrm{CC}$ \\
\hline $\mathrm{Rx}$ & T. pusilla & EY182905 & $\mathrm{CC}$ \\
\hline $\mathrm{Rx}$ & S. hermonthica & FS446680 & $\mathrm{CC}$ \\
\hline $\mathrm{Rx}$ & Olea europaea & GO244368 & $\mathrm{CC}$ \\
\hline $\mathrm{Rx}$ & Antirrhinum majus & AJ796877 & $\mathrm{CC}$ \\
\hline $\mathrm{NRG} 1^{\mathrm{c}}$ & Antirrhinum majus & AJ568282 & ADR1 \\
\hline NRG1 & M. guttatus & GR052998 & ADR1 \\
\hline NRG1 & T. pusilla & EY157110 & ADR1 \\
\hline NRG1 & M. gutattus var. nastus & GO955158 & $\mathrm{CC}$ \\
\hline NRG1 & O. europaea & GO244368 & $\mathrm{CC}$ \\
\hline NRG1 & S. hermonthica & FS444876 & $\mathrm{CC}$ \\
\hline StADR1 & M. guttatus & GR052998 & ADR1 \\
\hline StADR1 & Antirrhinum majus & AJ568282 & ADR1 \\
\hline StADR1 & T. pusilla & EY157110 & ADR1 \\
\hline StADR1 & S. hermonthica & FS444876 & $\mathrm{CC}$ \\
\hline StADR1 & M. gutattus var. nastus & GO955158 & $\mathrm{CC}$ \\
\hline StADR1 & O. europaea & GO244368 & $\mathrm{CC}$ \\
\hline \multicolumn{4}{|c|}{ Aquilegia coerulea } \\
\hline $\mathrm{N}$ & A. coerulea Goldsmith & $002643 m$ & $\mathrm{CC}$ \\
\hline $\mathrm{N}$ & A. coerulea Goldsmith & $025091 \mathrm{~m}$ & $\mathrm{CC}$ \\
\hline $\mathrm{N}$ & A. coerulea Goldsmith & $022597 \mathrm{~m}$ & $\mathrm{CC}$ \\
\hline $\mathrm{N}$ & A. coerulea Goldsmith & $019262 \mathrm{~m}$ & $\mathrm{CC}$ \\
\hline $\mathrm{N}$ & A. coerulea Goldsmith & $027686 \mathrm{~m}$ & $\mathrm{CC}$ \\
\hline $\mathrm{Rx}$ & A. coerulea Goldsmith & $019145 \mathrm{~m}$ & $\mathrm{CC}$ \\
\hline $\mathrm{Rx}$ & A. coerulea Goldsmith & $016085 \mathrm{~m}$ & $\mathrm{CC}$ \\
\hline $\mathrm{Rx}$ & A. coerulea Goldsmith & $013701 \mathrm{~m}$ & $\mathrm{CC}$ \\
\hline $\mathrm{Rx}$ & A. coerulea Goldsmith & $023629 \mathrm{~m}$ & $\mathrm{CC}$ \\
\hline $\mathrm{Rx}$ & A. coerulea Goldsmith & $027189 \mathrm{~m}$ & $\mathrm{CC}$ \\
\hline
\end{tabular}

${ }^{\mathrm{a}}$ Identifier for Lamiales = GenBank accession number, for Aquilegia coerule $a=$ transcript name (AcoGoldSmith_v1.)

${ }^{\mathrm{b}} \mathrm{ADR} 1=$ activated disease resistance gene 1 -like and $\mathrm{CC}=$ canonical coiled-coil nucleotide-binding, leucine-rich repeat.

${ }^{\mathrm{c}} \mathrm{NRG} 1=\mathrm{N}$-required gene 1. though they are shown to occupy a basal position in Figure 2, gymnosperm-derived sequences can be seen alternately to group with ADR1-like sequences depending on the protein domain analyzed. Thus, it remains to be determined whether gymnosperm $\mathrm{CC}_{\mathrm{R}}$-NB-LRR-encoding genes bear more affinity to one group or whether they, in fact, originated before the divergence of ADR1 and NRG1 lineages.

\section{Correlation of NRG1 and TIR-NB-LRR occurrence.}

Although ADR1-like sequences were identified in the genomes of every angiosperm species investigated, there are certain exceptions concerning the NRG1 group. Most notable among these is the absence of NRG1-like sequences from the genomes of every monocot species examined (Fig. 2). Interestingly, this trend correlates with the absence of TIR-NB-LRR proteins among monocots (Bai et al. 2002; McHale et al. 2006; Meyers et al. 1999). We were also unable to identify NRG1 homologs in the genomes of the dicots monkey flower (Mimulus guttatus) and columbine (Aquilegia coerulea), both in our original BLASTP searches as well as in subsequent TBLASTN searches using NbNRG1 as a query (data not shown). Both to confirm this finding and to investigate whether NRG1 and TIRNB-LRR occurrence might be correlated in these genomes as well, we undertook further investigation of these species' NBLRR complements. BLASTP searches of the Phytozomecurated M. guttatus proteome (Mimulus Genome Project, DOE Joint Genome Institute) using $\mathrm{Rx}$ and $\mathrm{N}$ as queries revealed an abundance of CC-NB-LRR proteins but no TIR-NB-LRR proteins (data not shown). Because such a condition is unlikely to be confined to a single species, we extended our investigation to the order Lamiales, of which monkey flower is a member. This was accomplished by searching GenBank Lamiales EST, based on the NB-ARC regions of StADR1 (discussed below), NbNRG1, Rx, and N, all of which are derived from the Solanales, a sister group to the Lamiales (Chase and Reveal 2009). For each of the four searches, the top hit from each of the first six occurring species or varieties was collected, such that six sequences were compiled per search (Table 1). Although definitive conclusions cannot be made in the absence of additional fully sequenced genomes, there are, nonetheless, approximately 540,000 Lamiales EST currently available in GenBank. We were able to identify three Lamiales $\mathrm{CC}_{\mathrm{R}}-\mathrm{NB}$ LRR EST, all of which grouped with ADR1 rather than NRG1 (Fig. 3A). Furthermore, searches performed with $\mathrm{N}$ as a query returned exclusively CC-NB-LRR sequences. Thus, all Lamiales EST sequences analyzed belonged either to the canonical CCNB-LRR or the ADR1-like groups (Fig. 3A; Table 1). As such, our findings are consistent with an absence of both NRG1 homologs and TIR-NB-LRR-encoding genes in the order Lamiales. These findings are also consistent with those of McHale and associates (2006), whose analysis of available NB-ARC sequences, though not exhaustive, failed to identify any Lamiales-derived TIR-NB-LRR members.

In the case of columbine, minimal sequence resources available for related species precluded analysis at the family or order level. Therefore, we confined our examination to the Phytozome-curated $A$. coerulea proteome (DOE Joint Genome Institute). Having already determined columbine's $\mathrm{CC}_{\mathrm{R}}-\mathrm{NB}$ LRR complement, we simply performed BLASTP searches with the Rx and N NB-ARC domains as queries, compiling the top five hits from each search (Table 1). Phylogenetic analysis of this dataset revealed that all sequences recovered grouped with CC-NB-LRR proteins, indicating an absence of TIR-NBLRR-encoding genes from the A. coerulea genome (Fig. 3B). Thus combined data from monocots, Lamiales, and columbine indicates a strong association between the occurrence of NRG1-like and TIR-NB-LRR-encoding genes. 
Sequence analysis of the $\mathbf{C C}_{\mathrm{R}}$ domain.

Although conserved domain searches of $\mathrm{CC}_{\mathrm{R}}$-NB-LRR proteins identify an RPW8 domain (RPW8 superfamily; PF05659, Pfam database available online from the Sanger Institute) at the $\mathrm{N}$ terminus, this similarity has received relatively little attention. Using alignments of all angiosperm sequences represented in Figure 2, we constructed separate NRG1-like and ADR1-like $C_{R}$ domain consensus sequences. We also constructed an RPW8 consensus, based on Arabidopsis Ms-0 RPW8.1 and RPW8.2 and Col-0 HR2 and HR3. We then aligned these consensuses, along with four representative sequences from each group, in order to examine the nature of sequence similarity between canonical RPW8 homologs and $\mathrm{CC}_{\mathrm{R}}$ domains (Fig. 4). Positions where residues are functionally similar between the three groups are evenly distributed over most of the sequence length (Fig. 4, pink). These are interspersed with residues conserved solely among $\mathrm{CC}_{\mathrm{R}}$ domains or specifically among either ADR1 or NRG1 homologs (Fig. 4, blue). Similarity largely ends at a position corresponding to RPW8.2 amino acid 144. After this point, there is no similarity between RPW8 proteins and $\mathrm{CC}_{\mathrm{R}}$ domains and very little similarity preserved among $\mathrm{CC}_{\mathrm{R}}$ domains. Because this poor sequence conservation is at the end of the functionally defined $\mathrm{CC}_{\mathrm{R}}$ domain, continuing until the beginning of the $\mathrm{NB}$ domain, it likely represents a linker region between the two domains (Fig. 4, gray bracket).

RPW8 is described as having two C-terminal CC structures (Fig. 4, black underlines) (Xiao et al. 2001). We analyzed each of the 12 representative sequences from Figure 4 with the COILS prediction program (Lupas et al. 1991) (available online from the Swiss Institute of Bioinformatics EMBnet), and indicate the location of the best-predicted $\mathrm{CC}$ structures for NRG1-like and ADR1-like groups as blue underlines in Figure 4. However, coiled coil predictions for $\mathrm{CC}_{\mathrm{R}}$ domains were rarely as strong as for RPW8 proteins (Supplementary Fig. S3). Given this lack of consistent prediction, it is uncertain whether $\mathrm{CC}$ are a relevant structural feature of $\mathrm{CC}_{\mathrm{R}}$ domains.
Sequence similarity between RPW8 proteins and $\mathrm{CC}_{\mathrm{R}}$ domains extends to the extreme N-terminus which, in RPW8, has been proposed to constitute a transmembrane (TM) domain. We were unable to identify any similarly conserved TM predictions among $\mathrm{CC}_{\mathrm{R}}$-NB-LRR proteins. Although RPW8.1, RPW8.2, HR2, and HR3 are all predicted by ConPredII (available online from Hirosaki University) to possess TM domains at their N-termini, only NbNRG1, AtNRG1.2, and Populus trichocarpa 0007s11510 (an NRG1 group member) out of all sequences included in Figure 2 receive similar TM predictions. Therefore, it is uncertain whether the $\mathrm{N}$-terminal sequence conservation between RPW8 proteins and $\mathrm{CC}_{\mathrm{R}}$ domains is indicative of functional conservation.

It is interesting to note that, whereas the majority of $\mathrm{CC}_{\mathrm{R}}$ domains do not possess a predicted TM domain, those that do all belong to the NRG1 rather than the ADR1 subclass. To further elucidate the relationship between NRG1 and ADR1 $\mathrm{CC}_{\mathrm{R}}$ domains and RPW8 domains, we constructed a phylogeny from the $\mathrm{CC}_{\mathrm{R}}$ domains of sequences included in Figure 2, as well as RPW8 domains of Arabidopsis RPW8.1, RPW8.2, HR1, HR2, HR3, and HR4 (Fig. 5). This analysis again illustrates a clear division between NRG1 and ADR1 groups, and also suggests that RPW8 homologs share more similarity with NRG1 rather than ADR1 $\mathrm{CC}_{\mathrm{R}}$ domains. Remarkably, RPW8 homologs are in fact placed within the NRG1 group, albeit distinguished from other group members by a fairly long branch.

\section{Similar defense response induction by NRG1 and ADR1 homologs.}

To expand our functional analysis to ADR1-like proteins, we cloned an ADRI homolog from potato, hereafter referred to as StADRI (GenBank accession number HQ906887), based on available potato genome sequence. We found that transient expression of the first 155 amino acids (terminating a few residues into the linker region) was sufficient to induce a rapid $\mathrm{HR}$ in tobacco and $N$. benthamiana (Fig. 6A). We also cloned the $\mathrm{CC}_{\mathrm{R}}$-encoding domains of Arabidopsis ADR1 (At1g33560),
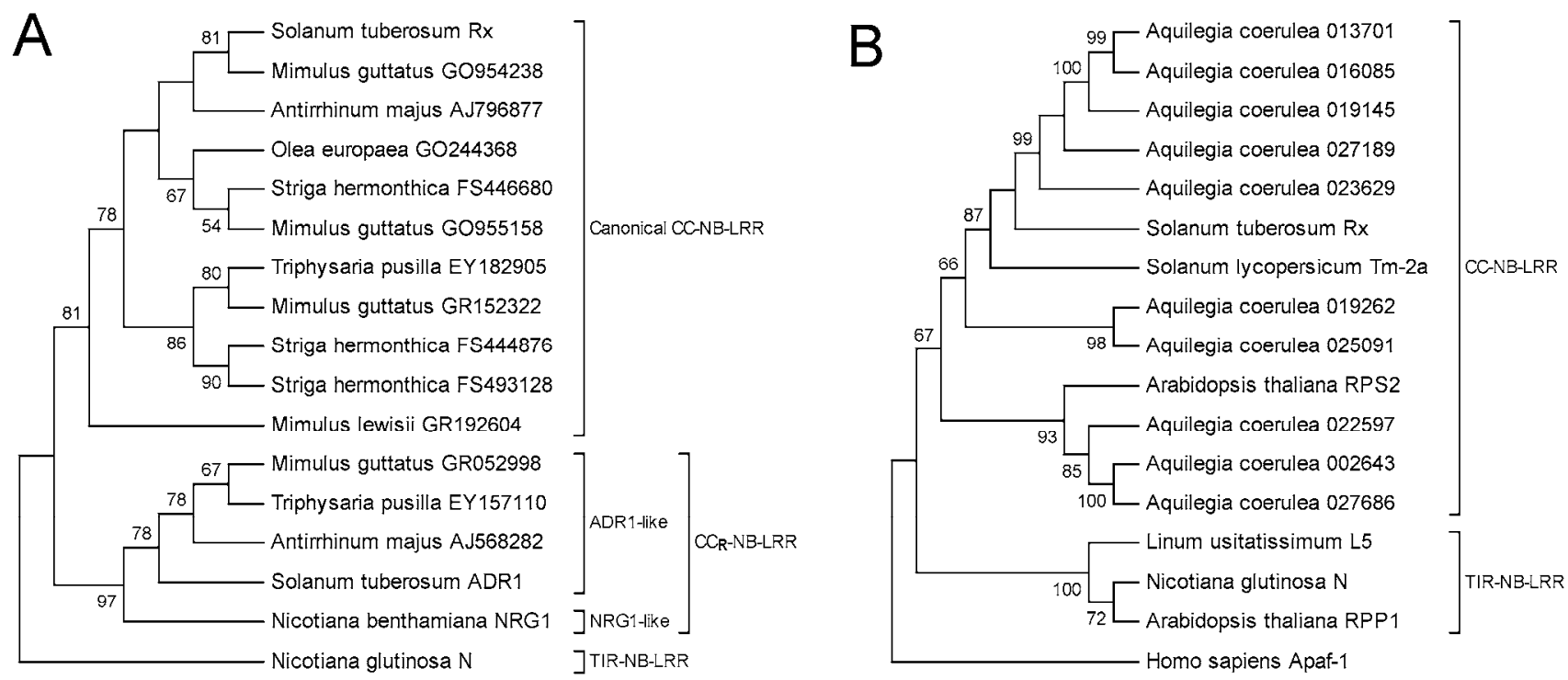

Fig. 3. Absence of Toll and interleukin-1 receptor (TIR) nucleotide-binding, leucine-rich repeat (NB-LRR) sequences from Lamiales and Aquilegia coerulea. A, Phylogenetic analysis of Lamiales expressed sequence tag sequences compiled from BLAST searches querying with Solanum tuberosum activated disease resistance gene 1 (ADR1), Nicotiana benthamiana N-required gene 1 (NbNRG1), Rx, and N sequences. Query sequences are also included as points of reference. The tree was constructed by neighbor-joining (NJ) from an alignment of internal NB Apaf-1, R proteins, and CED4 homology (ARC) sequence corresponding to NbNRG1 amino acids 110 to 176. B, Phylogenetic analysis of Aquilegia coerulea NB-LRR sequences compiled by querying the genome with Rx and N sequences. Sequences from coiled-coil-NB-LRR proteins Rx, Arabidopsis thaliana RPS2, and Solanum lycopersicum Tm-2a, and from TIRNB-LRR proteins N, A. thaliana RPP1, and Linum usitatissimum L5, are also included as points of reference. The tree was constructed by NJ and based on aligned NB-ARC domain sequences, and is rooted with human Apaf-1. For both trees, bootstrap values are based on 1,000 replicates, and percent values over 50 are displayed at branch points. 
ADR1-L1 (At4g33300), ADR1-L2 (At5g04720), At5g66900, and At5g66910. We refer to the latter two genes as AtNRG1.1 and AtNRG1.2, respectively, based on their similarity to $N$. benthamiana NRG1. Of these, the AtADR1 and AtNRG1.2 $\mathrm{CC}_{\mathrm{R}}$ domains consistently induced a rapid and strong HR upon transient expression, while those of AtADR1-L1, AtADR1-L2, and AtNRG1.1 induced mild chlorosis (Fig. 6A). Thus, $\mathrm{CC}_{\mathrm{R}^{-}}$ mediated HR induction is a common property of both $\mathrm{CC}_{\mathrm{R}^{-}}$ NB-LRR clades and is conserved among different plant families. Interestingly, although solanaceous $\mathrm{CC}_{\mathrm{R}}$ domains produced a strong HR in tobacco, their effect was weaker in $N$. benthamiana, whereas some $A$. thaliana-derived $\mathrm{CC}_{\mathrm{R}}$ domains showed an opposite pattern. In a striking example, NRG1.2 produced a strong HR in $N$. benthamiana but yielded only mild chlorosis in tobacco (Fig. 6A). These differences were not due to differences in protein expression, however, because $\mathrm{CC}_{\mathrm{R}}$ domains were expressed at similar levels in both species (Fig. 6B). These observations suggest that the ability of a given $\mathrm{CC}_{\mathrm{R}}$ domain to induce an HR may be affected by genetic background.

Overexpression of full-length NRG1 has been reported to induce defense responses and suppress viral accumulation in the absence of an HR (Peart et al. 2005). We tested whether this activity was common to ADR1 as well by co-expressing full-length NbNRG1 and StADR1 with a version of Potato virus $X$ expressing green florescent protein (PVX:GFP). Indeed, StADR1 reduced the amount of GFP accumulation from PVX:GFP as judged both visually and by anti-PVX coat pro- tein (CP) immunoblotting (Fig. 6C and D), indicating that, like NbNRG1, it is able to induce antiviral defense responses in the absence of a visible HR. We similarly tested non-HR-inducing Arabidopsis $\mathrm{CC}_{\mathrm{R}}$ domains and found that their expression also caused reduced viral replication (Fig. 6C and D), indicating that these $\mathrm{CC}_{\mathrm{R}}$-NB-LRR proteins also have the capacity to induce a genuine resistance response.

\section{$\mathrm{CC}_{\mathrm{R}}$ signaling is SGT1-independent.}

Many CC-NB-LRR proteins require SGT1 to function, due to a dependence on SGT1-containing chaperone complexes for proper folding and accumulation (Kadota et al. 2010). The suppression of viral replication associated with full-length NbNRG1 overexpression is compromised in SGT1-silenced plants (Peart et al. 2005). We investigated whether this SGT1 functional dependency extends to $\mathrm{CC}_{\mathrm{R}}$-mediated signaling as well. As expected, HR induction by both a constitutively active full-length CC-NB-LRR protein (Rx D460V) and by the Rx NB domain (NB:eGFP), both of which induce an HR within the same timeframe as the NRG1 $C_{R}$ domain, was abolished in plants where SGT1 levels had been reduced by virus-induced gene silencing (VIGS) (Fig. 7). In contrast, HR induced by NbNRG1 and StADR1 $C_{R}$ domains were not affected by SGT1 silencing, nor was cell death induced by the mouse Bax protein used as a control (Fig. 7). Thus, although full-length $\mathrm{CC}_{\mathrm{R}}$-NB-LRR proteins may require SGT1, the ability of $\mathrm{CC}_{\mathrm{R}}$ domains to initiate signaling does not appear to require SGT1, at least not at the levels required for other strong HR inducers.
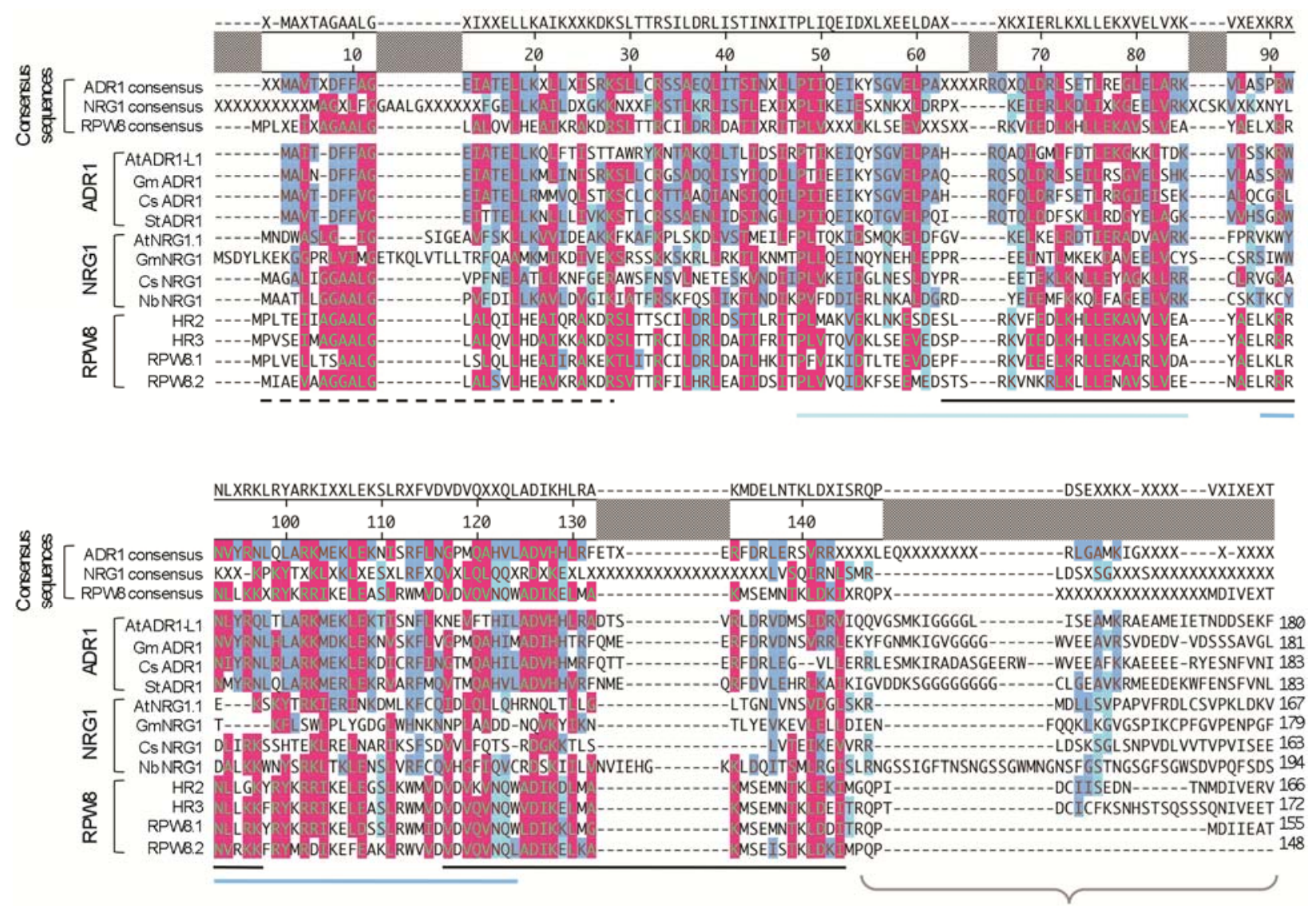

Fig. 4. Multiple sequence alignment of coiled-coil domains resembling the Arabidopsis thaliana RPW8 protein $\left(\mathrm{CC}_{\mathrm{R}}\right)$. Consensus sequences for $\mathrm{ADR} 1$, NRG1, and RPW8 protein groups are displayed at top, with four representatives from each group displayed below ( $\mathrm{Gm}=$ Glycine max and Cs $=$ Cucumis sativus) The ruler at top is of RPW8.2. Where a majority of residues are functionally similar to the RPW8 consensus sequence, those residues are highlighted in pink. Additional regions of conservation corresponding to the ADR1 and NRG1 consensus sequences are highlighted in shades of blue. Black underlines correspond to the two predicted CC structures of RPW8.2 and a dashed black underline corresponds to the RPW8.2 predicted transmembrane domain or signal peptide. Blue underlines indicate locations of the most strongly predicted CC structures from NRG1-like and ADR1-like groups. Gray bracket indicates the location of probable $\mathrm{CC}_{\mathrm{R}}$-nucleotide-binding linker sequence. 


\section{$C_{R}-N B-L R R$ requirement}

in CC-NB-LRR-mediated disease resistance.

Given that NRG1 is required for the function of at least one NB-LRR protein, we were interested in whether this might represent a larger trend, and whether ADR1 might also be prerequisite for the activities of certain NB-LRR proteins. Therefore, we constructed VIGS vectors to silence either NRG1, $A D R 1$, or both $N R G 1$ and $A D R 1$ combined, using an $N R G 1$ sequence from $N$. benthamiana and $A D R l$ sequence from $N$. tabacum. $N$. benthamiana possesses a single functional copy of NRG1 (Peart et al. 2005) and we were able to identify only single $A D R l$-like sequences from tobacco, tomato (S. lycopersicum), and potato-suggestive of single-copy status within the family Solanaceae. Thus, the genus Nicotiana provides a more tractable system than A. thaliana, which possesses multiple copies of both $N R G 1$ and $A D R 1$, some arrayed in tandem. $N R G 1$ VIGS has previously been reported to efficiently break $\mathrm{N}$ - but not Rx-mediated virus resistance. However, Rx induces an exceptionally strong resistance response which may be difficult to break with gene knockdown techniques such as VIGS (Sacco et al. 2007). $R x 2$ is a paralog of $R x$, with similar recognition specificity for the PVX CP but with weaker resistanceinducing activity compared with $R x$ (Bendahmane et al. 2000). Therefore, we used $N$. benthamiana expressing $R \times 2$ as a trans- gene in VIGS experiments (Bhattacharjee et al. 2009). Silenced plants were rub inoculated with PVX:GFP and subsequently monitored for breakage of resistance, which manifested as trailing necrosis - the result of virus escape followed by delayed defense-response induction (Fig. 8B). VIGS using the empty vector leads to a low level of spontaneous resistance breaking, and silencing of NRGl or ADRl alone had little additional effect on Rx2-mediated resistance. However, silencing of $N R G 1$ and $A D R 1$ together resulted in a consistent increase in the frequency of Rx2 breakage to nearly fourfold that of the empty vector control (Fig. 8A), suggesting some involvement of $\mathrm{CC}_{\mathrm{R}}$-NB-LRR proteins in Rx2-mediated resistance.

\section{DISCUSSION}

We show here that ADR1 and NRG1 homologs constitute a family of proteins whose $\mathrm{N}$ termini possess activities not observed for canonical CC-NB-LRR proteins. These homologs are easily identifiable between distantly related plant species, and phylogenetic analysis suggests that these proteins have been retained for one or more conserved functions, in contrast to other NB-LRR protein families, which have undergone a great deal of diversification and amplification. As such, we suggest that this family of proteins represents a unique set of

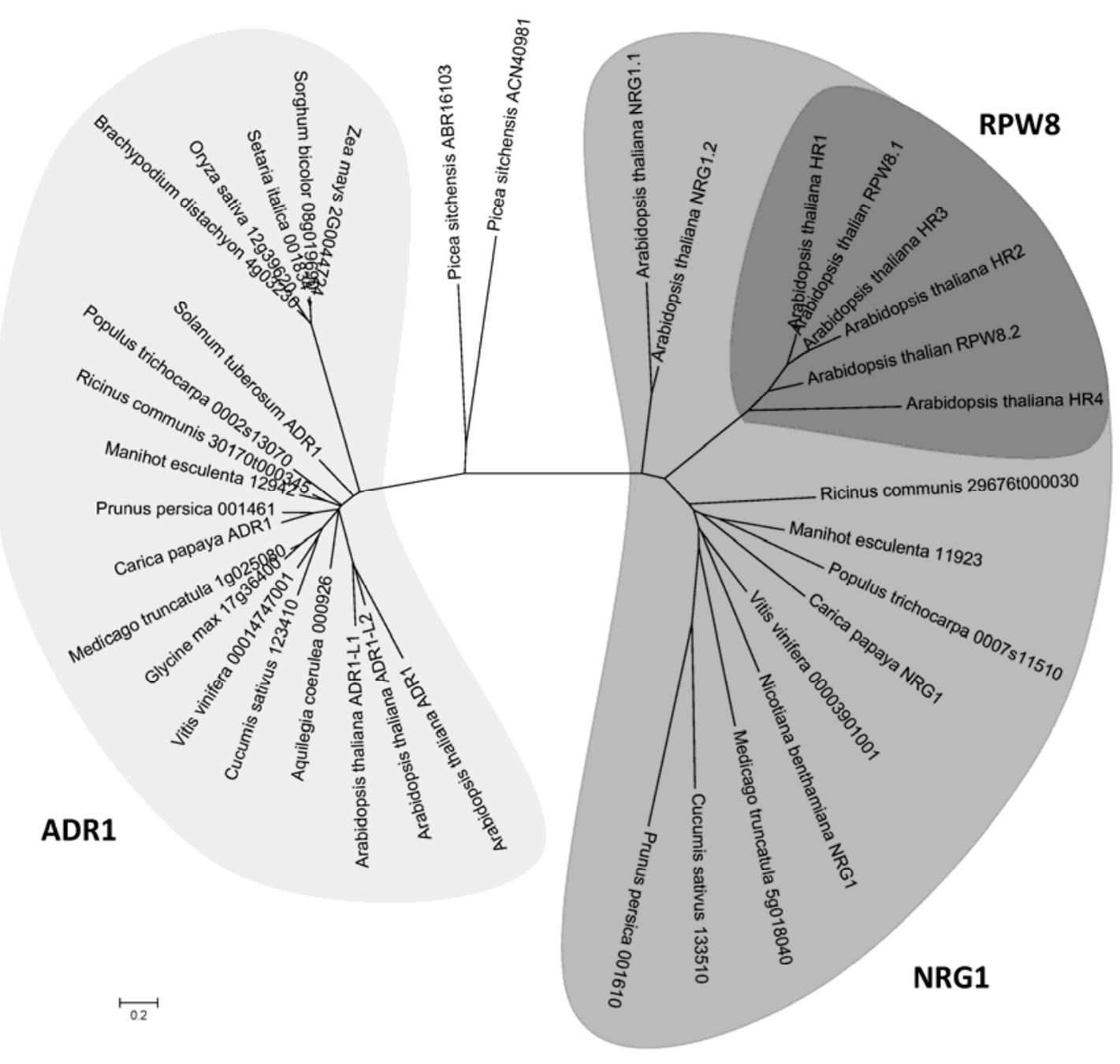

Fig. 5. Phylogenetic analysis of coiled-coil domains resembling the Arabidopsis thaliana RPW8 protein (CC $\left.\mathrm{R}_{\mathrm{R}}\right)$ and $\mathrm{RPW} 8$ domains. Bootstrap consensus tree from the aligned $C_{R}$ and RPW8 internal region corresponding to RPW8.2 positions 27 to $135 . C_{R}$ domains are from core sequences used in previous phylogenetic analyses, after removal of any sequences with incomplete $\mathrm{N}$-terminal coverage. The tree was constructed by neighbor-joining and is drawn to scale, with branch lengths corresponding to evolutionary distance. The scale bar is in units of amino acid substitutions per site. ADR1-like, NRG1-like, and RPW8 groups are indicated by background shading. 
NB-LRR proteins and propose that they be referred to hereafter as $C_{R}$-NB-LRR proteins in order to differentiate them from other NB-LRR proteins.

\section{The $\mathrm{CC}_{\mathrm{R}}$ domain.}

The $\mathrm{CC}_{\mathrm{R}}$ domains of both NRG1- and ADR1-like proteins bear similarity to RPW8 across the majority of their sequence, interspersed with regions of conservation shared only among NRG1 and ADR1 homologs (Fig. 4). Although the proteins encoded by RPW8 homologs are strongly predicted to form CC structures, such predictions for $\mathrm{CC}_{\mathrm{R}}$ domains are typically weaker and less consistent. Therefore, whether a CC structure has any relevance to $C_{R}$ function is uncertain. It is striking that the similarity between $\mathrm{CC}_{\mathrm{R}}$ domains and RPW8 extends to the extreme $\mathrm{N}$ terminus which, in RPW8, is predicted to contain a transmembrane domain and signal peptide, thought to be critical to its targeting to the extrahaustorial membrane during powdery mildew infection (Wang et al. 2009; Xiao et al. 2001). However, because similar transmembrane and targeting functional predictions are uncommon among $\mathrm{CC}_{\mathrm{R}}$ sequences, the relevance of this sequence conservation remains to be determined. Indeed, it is noteworthy that NbNRG1 (1 to 225) migrates more slowly than NbNRG1 (13 to 225) during sodium dodecyl sulfate polyacrylamide gel electrophoresis (Fig. 1A), which would not be the case if a canonical signal peptide had been cleaved from the former during translocation to the endoplasmic reticulum. An additional question raised by this analysis is whether RPW8 is derived from $C_{R}-N B-L R R$ proteins or vise versa, or whether they arose from a common precursor. Notably, whereas we have found $\mathrm{CC}_{\mathrm{R}}$-NB-LRR genes to be present in every seed plant species examined, RPW8 homologs have thus far been identified only among members of the family Brassicaceae (Xiao et al. 2004), arguing against an ancient origin for the RPW8 gene family. This observation, combined with our placement of RPW8 homologs within the NRG1 clade (Fig. 5), suggests that RPW8 homologs may have originated as an offshoot of $\mathrm{CC}_{\mathrm{R}}$-NB-LRR proteins, likely deriving from the NRG1 group.

Avr-independent HR induction by fragments of NB-LRR proteins is a useful tool for determining the domains involved
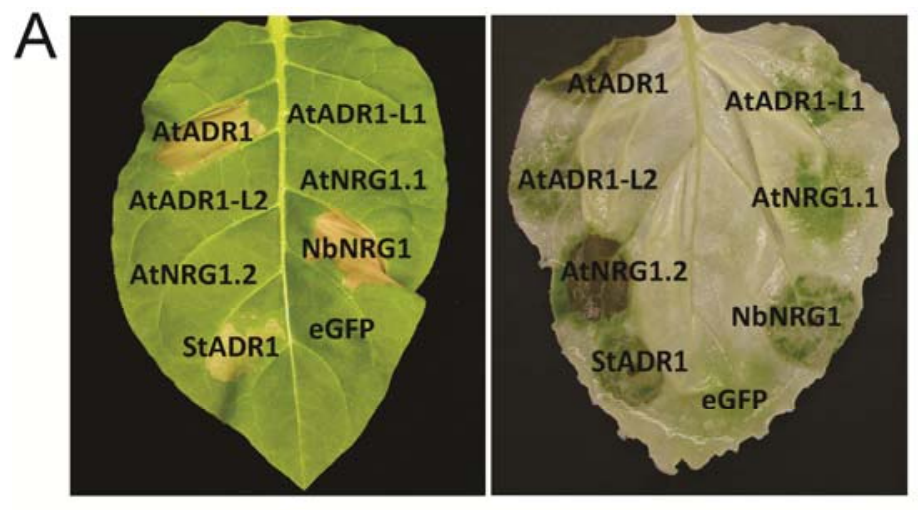

B
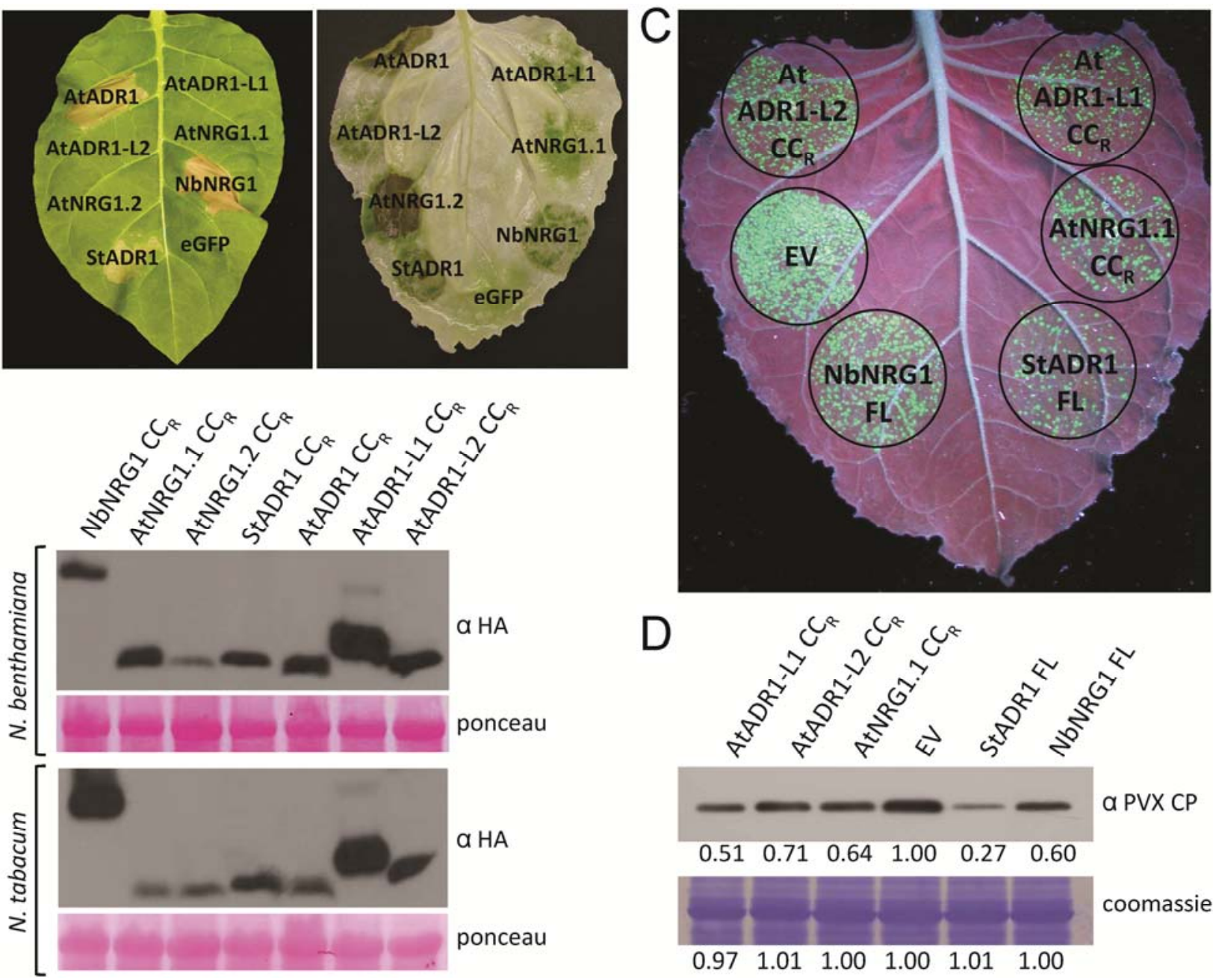

Fig. 6. Defense response induction by coiled-coil domains resembling the Arabidopsis thaliana $\mathrm{RPW} 8$ protein $\left(\mathrm{CC}_{\mathrm{R}}\right)$. A, NRG1 and ADR1 CC $\mathrm{R}_{\mathrm{R}}-\mathrm{mediated}$ hypersensitive response (HR) in tobacco (left panel) and Nicotiana benthamiana (right panel), the latter having been ethanol cleared to enhance visibility. Leaves were photographed 3 days after agroinfiltration with the indicated hemagglutinin (HA)-tagged Arabidopsis or solanaceous CC $\mathrm{R}_{\mathrm{R}}$ domains. Note the NbNRG1 $\mathrm{CC}_{\mathrm{R}}$ corresponds to the construct 1 to 225 . B, Protein extracts from agroinfiltrated patches of $N$. benthamiana or $N$. tabacum leaves, as indicated in A, were subjected to anti-HA immunoblotting after $24 \mathrm{~h}$. Equal loading was verified by ponceau staining. C, Potato virus $X$ expressing green florescent protein (PVX:GFP) accumulation after co-infiltration with non-HR-inducing $\mathrm{CC}_{\mathrm{R}}$ nucleotide-binding, leucine-rich repeat (NB-LRR) variants. GFP was visualized 5 days after agroinfiltration by handheld UV lamp. D, Five days after agroinfiltration, protein extracts from C were subjected to immunoblotting with antibody against the PVX coat protein (CP) (top panel). Equal loading was verified by Coomassie staining (bottom panel). For quantification of protein levels (listed below each band), average gray values from nonsaturated exposures (PVX CP) or total protein bands (Coomassie) were measured and converted to a scale where the empty vector $(\mathrm{EV})$ measurement $=1.0$. All experiments were performed at least three times with similar results. 
in signal initiation (Krasileva et al. 2010; Rairdan et al. 2008; Swiderski et al. 2009). We have demonstrated that $\mathrm{CC}_{\mathrm{R}}$ domains of both NRG1 and ADR1 homologs are able to trigger HR. We have further shown this to be part of a bona fide resistance response, capable of restricting viral accumulation (Fig. 6). Because $C_{R}$-mediated defense response induction is found not only among solanaceous homologs but also among NRG1 and ADR1 homologs from A. thaliana, it is likely that this is a common feature of $\mathrm{CC}_{\mathrm{R}}$ domains. Thus, the $\mathrm{N}$ termini of $\mathrm{CC}_{\mathrm{R}^{-}}$ NB-LRR proteins appear to function quite differently from those of canonical CC-NB-LRR proteins which, by themselves, have only been shown to mediate recognition (Collier and Moffett 2009).

The function of many CC-NB-LRR proteins, including fulllength NRG1, depend on the presence of SGT1 for proper folding and accumulation, presumably through interaction with the LRR domain (Bieri et al. 2004; Kadota et al. 2010; Leister et al. 2005; Peart et al. 2005; Zhang et al. 2008). Furthermore, signal
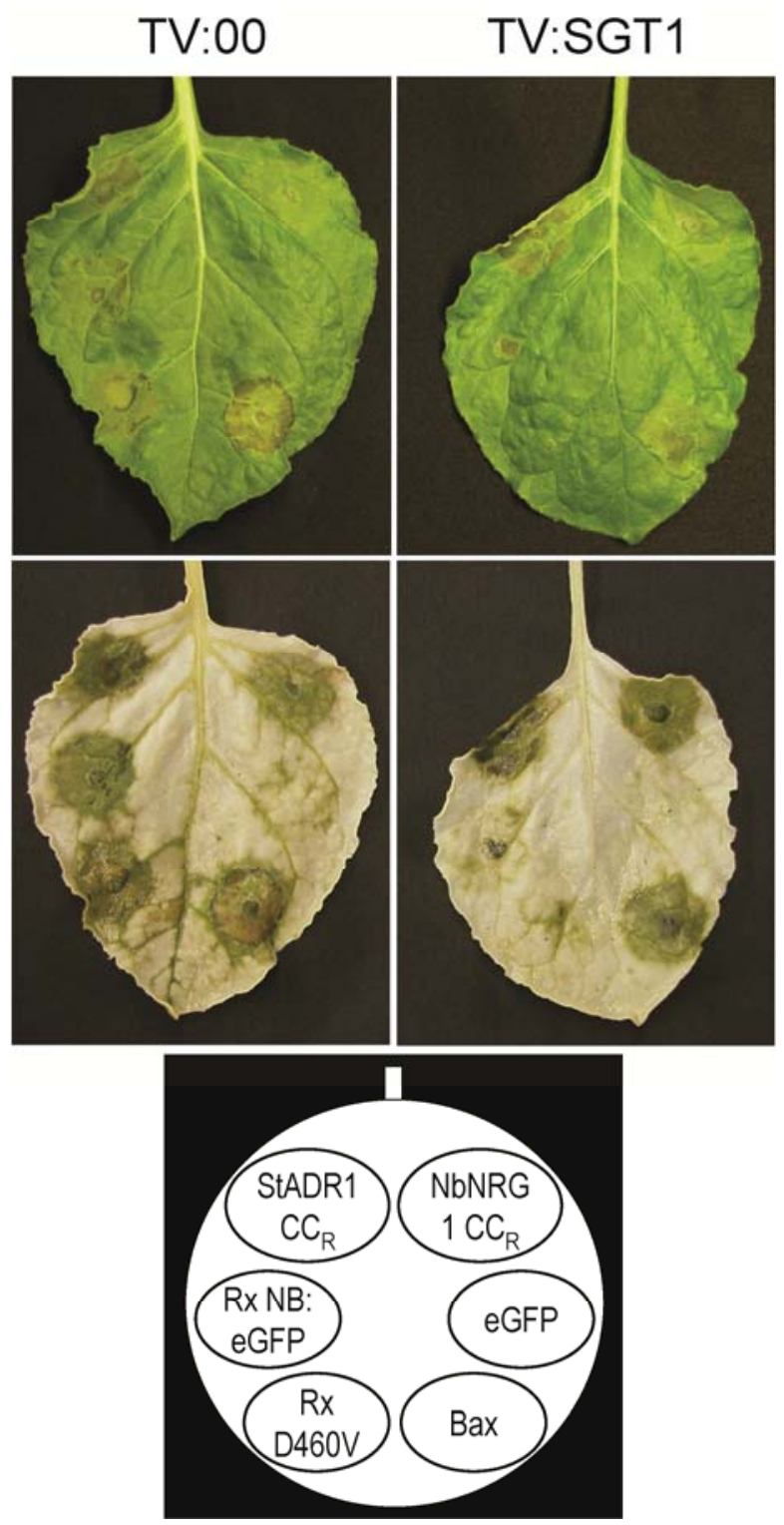

Fig. 7. Coiled-coil domain resembling the Arabidopsis thaliana RPW8 protein $\left(\mathrm{CC}_{\mathrm{R}}\right)$-mediated hypersensitive response (HR) induction is SGT1 independent. Plants silenced for SGT1 (TV:SGT1, right) or infected with Tobacco rattle virus empty vector control (TV:00, left) were agroinfiltrated with the constructs indicated (bottom panel). Leaves were photographed 5 days later. before (top panels) and after (middle panels) ethanol clearing. initiation by the Rx NB domain retains its SGT1-dependence (Rairdan et al. 2008), suggesting a similar requirement for SGT1 by some proteins which function downstream of $\mathrm{Rx}$ activation. Therefore, it is noteworthy that the HR induced by NbNRG1 and StADR $1 \mathrm{CC}_{\mathrm{R}}$ domains appear to be SGT1 independent (Fig. 7), likely because SGT1 is not required for the folding of the relatively simple $C_{R}$ domain alone. Thus, it is tempting to speculate that either $\mathrm{CC}_{\mathrm{R}}$ domains signal through different pathways than canonical CC-NB-LRR proteins or they function downstream of SGT1-dependent factors.

\section{$C_{R}$-NB-LRR evolution and evidence for functional requirement.}

The NB-LRR gene family is noted for its plasticity and rapid evolution, frequently featuring both gene duplication and gene loss during speciation (McDowell and Simon 2006; Sakai and Itoh 2010; Xu et al. 2011). Representation of various NB-

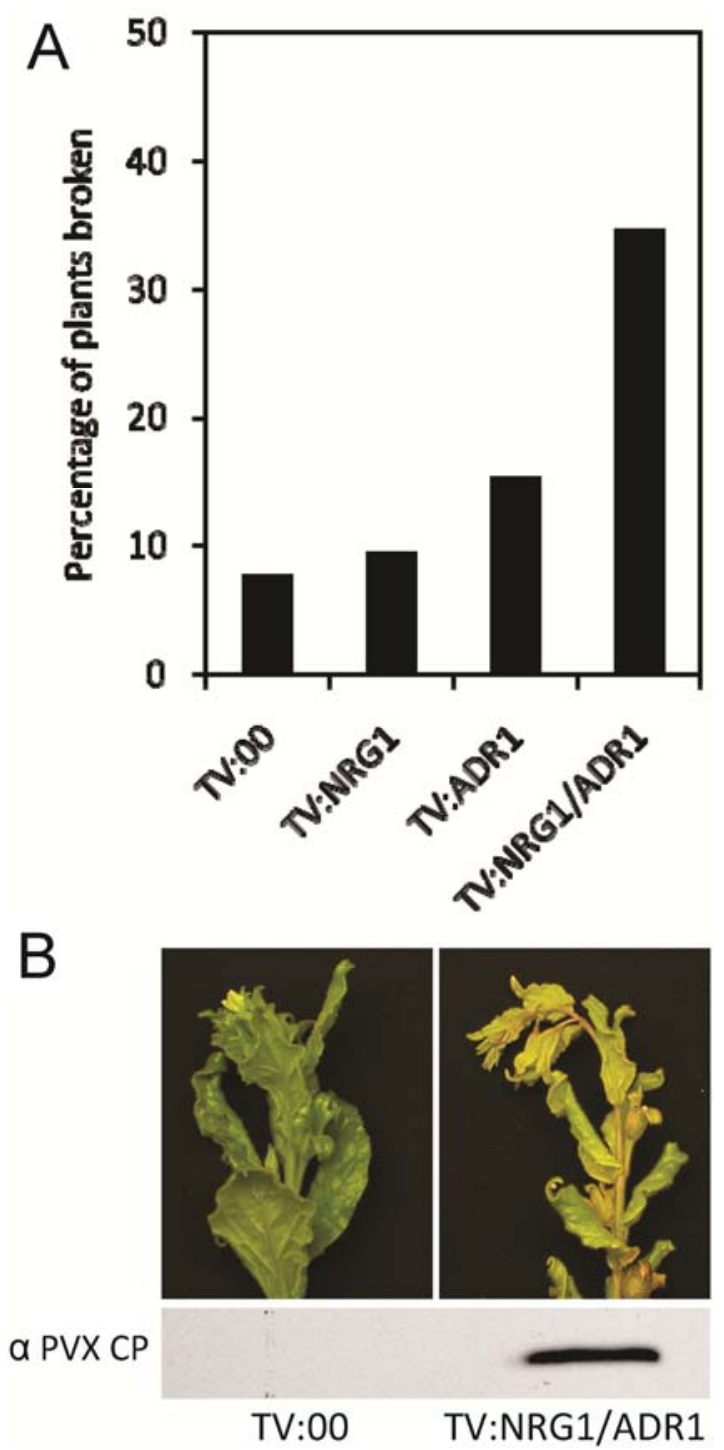

Fig. 8. Rx2-mediated resistance is partially compromised by combined NRG1 and ADR1 silencing. A, Percentage of plants displaying trailing necrosis following Potato virus $X$ expressing green florescent protein (PVX:GFP) inoculation, having previously been infected with the Tobacco rattle virus empty vector (TV:00) or silenced for NRG1, ADR1, or NRG1 + ADR1 by virus-induced gene silencing. B, Appearance of healthy (left) and diseased (right) plants (top panels) following PVX:GFP inoculation. All instances of resistance breaking were confirmed by anti-PVX coat protein (CP) immunoblotting, a representative example of which is shown (bottom panel). 
LRR lineages can vary greatly between species and, indeed, much variation is seen even at the broadest level of classification, with ratios of CC-NB-LRR- to TIR-NB-LRR-encoding genes ranging from greater than 10:1 in cocoa (Theobroma cacao) to less than 0.6:1 in A. thaliana (Argout et al. 2011; Velasco et al. 2010). Therefore, it is remarkable that at least one ADR1 homolog is present in every higher plant species examined, and that the ADR1 lineage has not undergone a sizable expansion in any of the species studied (A. thaliana and soybean [Glycine max] have the largest $A D R 1$ gene families, with four members each). Such a conservative evolutionary history suggests that ADR1 may perform some critical and specific function. Although this function might conceivably be the recognition of an uncommonly ubiquitous pathogen, possibly through the highly conserved LRR domain, it is perhaps more likely to play a more general role in disease resistance. $\mathrm{CC}_{\mathrm{R}}$-NB-LRR proteins might act directly downstream of canonical NB-LRR proteins. At the same time, it is tempting to speculate that they might behave in a manner similar to the animal NOD-like receptor NLRP3, which responds to perturbations in cellular ion concentrations and reactive oxygen species caused indirectly by infection (Tschopp and Schroder 2010). Were such the case, $C_{R}$-NB-LRR proteins might sense initial changes in cellular homeostasis and subsequently amplify resistance signaling capacity.

A specific interplay between $\mathrm{CC}_{\mathrm{R}}-\mathrm{NB}-\mathrm{LRR}$ proteins and canonical NB-LRR proteins is further suggested by the close association between NRG1 homologs and TIR-NB-LRR genes. Although $\mathrm{NbNRG1}$ was originally reported to be required exclusively by $\mathrm{N}$, the only other resistance proteins examined in a resistance assay for NRG1 requirement, Rx and Pto/Prf, were of the CC-NB-LRR rather than TIR-NB-LRR class (Peart et al. 2005). The correlation between the presence of both NRG1 homologs and TIR-NB-LRR genes presented here

suggests that the functional relationship between NRG1 and N may represent a broader trend rather than an isolated instance. NRG1-encoding sequences are absent from all monocot species examined (Fig. 2), mirroring the observation that monocots lack TIR-NB-LRR proteins (Bai et al. 2002; Meyers et al. 1999; Pan et al. 2000; Tarr and Alexander 2009). This absence was, until now, thought to be exclusive to monocots. However, we have found that NRGl homologs as well as TIR-NB-LRRencoding genes are also absent from the genomes of the dicots M. guttatus and Aquilegia coerulea (Fig. 3). Furthermore, in the case of $M$. guttatus, these absences are likely not limited to the species level but extend to other members of the order Lamiales as well (Table 1; Fig. 3).

The majority of fully sequenced dicot genomes belong to the rosid clade of core eudicots, with only a single basal eudicot (Aquilegia coerulea) and a single member of the asterid clade of core eudicots (M. guttatus). At first glance, one might speculate that the absence of NRGI homologs and TIR-NBLRR-encoding genes observed in monocots, Lamiales, and Aquilegia coerulea represent single gene loss events. However, this scenario is highly unlikely, particularly considering that the order Solanales - sister group to the order Lamiales and fellow member of the asterid clade (Chase and Reveal 2009)possesses members of both the TIR-NB-LRR and NRG1 lineages. Thus, any model of $T I R-N B-L R R$ evolution must account for the presence of this lineage in gymnosperms, rosids, and the Solanales, and a single gene loss event would necessarily correspond to TIR-NB-LRR-encoding genes having arisen independently on three occasions. Much more likely is an evolutionary path described by a single gene acquisition in a common ancestor of gymnosperms and angiosperms, followed by independent gene loss events in each of the three affected lineages (Fig. 9A). In considering how such a large gene family could be entirely lost from at least three independent lineages,

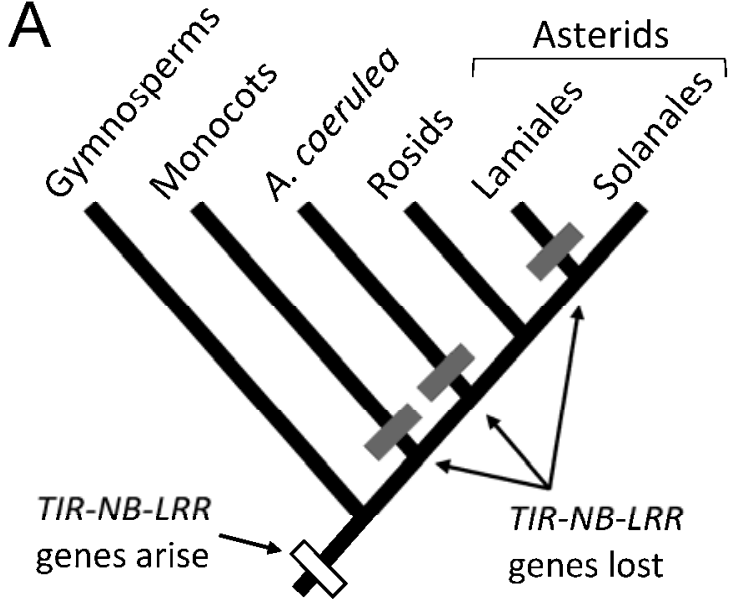

TIR-NB-LRR genes

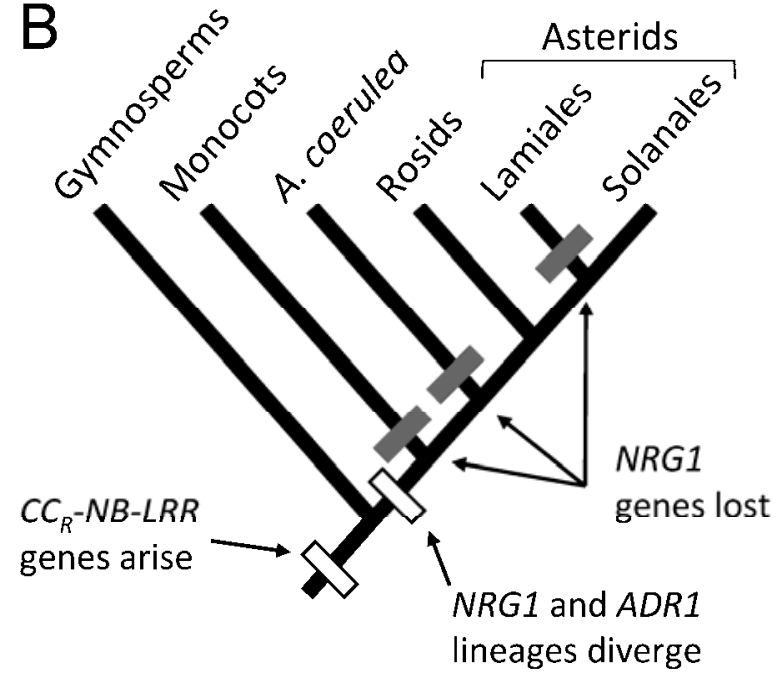

$C C_{R}-N B-L R R$ genes

\section{Gene acquisition}

\section{Gene loss}

Fig. 9. Evolutionary models for Toll and interleukin-1 receptor (TIR) nucleotide-binding, leucine-rich repeat (NB-LRR) and coiled-coil domain resembling the Arabidopsis thaliana RPW8 protein $\left(C_{\mathrm{R}}\right)$-NB-LRR lineages. A, Probable evolutionary path leading to the observed patterns of $T I R-N B$ - $L R R$ occurrence. TIR-NB-LRR genes, having arisen before the divergence of gymnosperms and angiosperms, are subsequently lost from monocot, Aquilegia coerulea, and Lamiales lineages. B, Probable evolutionary path which produces the observed patterns of NRG1 and ADR 1 occurrence. $C C_{R}-N B$ - $L R R$ genes having arisen before the divergence of gymnosperms and angiosperms, distinct $N R G 1$ and $A D R 1$ variants emerge within the angiosperm lineage and $N R G 1$ genes are subsequently lost from monocot, Aquilegia coerulea, and Lamiales lineages. 
it is interesting to note that preliminary analysis of the cocoa genome has identified only eight TIR-NB-LRR-encoding genes, less than $1 / 10$ the number of CC-NB-LRR-encoding genes identified (Argout et al. 2011). It is possible that cocoa represents a plant lineage en route to eliminating its TIR-NB-LRR-encoding genes, perhaps offering a glimpse of the gene family at a midpoint in the process of decline. At the same time, however, there is at least one $N R G l$ homolog present in the cocoa genome (locus Tc01_g004490) which, if functional, would make it unlikely that the loss of $T I R-N B-L R R$ genes is precipitated by the loss of NRG1.

The evolutionary pattern of NRGl homologs is somewhat more ambiguous than that of TIR-NB-LRR-encoding genes, owing largely to the uncertainty surrounding gymnosperm $\mathrm{CC}_{\mathrm{R}}$-NB-LRR-encoding genes. Although our analysis of gymnosperm-derived sequences clearly indicates that they form a single group, displaying no NRG1 versus ADR1 division, we were unable to resolve definitively whether this group predates the division of NRG1 and ADR1 or whether it might belong to a single clade (Figs. 2 and 5), thus calling into question the placement of NRG1-ADR1 divergence. Assuming that gymnosperms possess an ancestral form of a $C C_{R}-N B-L R R$ gene, the simple scenario whereby $N R G 1$ arises in the ancestor of core eudicots and is subsequently lost from the Lamiales lineage would explain the observed pattern of occurrence. However, this fails to address the fact that the split between NRG1 and ADR 1 is, as suggested by Figures 2 and 5, deeper than the split between monocots and dicots. Thus, NRG1 and ADR1 presumably diverged before the divergence of monocots and dicots. Therefore, the most plausible scenario is similar to that described for $T I R-N B-L R R$ genes, the only difference being differentiation of $N R G 1$ and $A D R 1$ lineages after the divergence of angiosperms and gymnosperms (Fig. 9B). Were the NRG1-ADR1 divergence to have occurred in a common ancestor of gymnosperms and angiosperms, the single $C_{R^{-}}-N B$ $L R R$ clade present in gymnosperms could only be explained by the loss of either NRG1 or ADRl homologs. This not only introduces additional evolutionary steps but is unsupported by evidence if either i) any plant species losing the $A D R l$ lineage or ii) TIR-NB-LRR proteins existing in angiosperms in the absence of NRG1 proteins. Thus, it is probable that gymnosperms, while possessing both CC-NB-LRR and TIR-NB-LRR proteins, possess an ancestral form of $\mathrm{CC}_{\mathrm{R}}$-NB-LRR proteins and, hence, the dynamics between canonical NB-LRR proteins-especially of the TIR-NB-LRR class-and $\mathrm{CC}_{\mathrm{R}}-\mathrm{NB}$ LRR proteins might be expected to be somewhat different in gymnosperms than in flowering plants.

Our phylogenetic analyses strongly suggest a critical role for ADR1-like proteins and a strong functional relationship between NRG1 and TIR-NB-LRR proteins. However, the corollary to this relationship, namely a requirement for ADR1-like proteins by CC-NB-LRR proteins, while intriguing, is not strictly supported by our data. Rather, we were surprised to find that, while silencing of $A D R 1$ or $N R G 1$ alone had no apparent impact on $\mathrm{Rx} 2$-mediated resistance, the combined silencing of $N R G 1$ and $A D R 1$ resulted in partially compromised resistance (Fig. 8). This suggests that, although the Rx2 CC-NB-LRR protein does rely to at least some extent on $\mathrm{CC}_{\mathrm{R}}$-NB-LRR proteins, the reliance is not specific to a particular clade. Therefore, we speculate that, whereas there may be an absolute requirement by TIR-NB-LRR proteins for NRG1-like proteins, CC-NB-LRR proteins may be able to utilize either NRG1- or ADR1-like proteins as necessary.

It is not yet clear how $\mathrm{CC}_{\mathrm{R}}$-NB-LRR proteins fit into the larger picture of NB-LRR protein recognition and signaling pathways. Nonetheless, we have identified multiple unique properties of this class with regards both to their evolutionary history and $\mathrm{N}$-terminal domains, which will have significant implications for our understanding of NB-LRR evolution and function. Although the extent to which $\mathrm{CC}_{\mathrm{R}}-\mathrm{NB}-\mathrm{LRR}$ proteins may be required by other classes of NB-LRR proteins is not yet fully known, our findings indicate that this unique NB-LRR lineage has an important role to play in plant resistance responses.

\section{MATERIALS \& METHODS}

\section{Sequence analysis.}

Database searches were performed between May and November 2010. All searches were performed with either BLASTP or TBLASTN on default settings. An initial cutoff of bit score 200 was used to estimate $C_{R}-$ NB-LRR homology in Phytozome proteome searches and, after phylogenetic confirmation, additional sequences were added or discarded to ensure that the data set contained all $\mathrm{CC}_{\mathrm{R}}$-NB-LRR homologs and one outgroup sequence. Both the papaya NRGI and ADRI homologs lack sequence coverage in some areas, resulting in segmented and incomplete protein predictions. Therefore, genomic sequence was manually analyzed to obtain sequences that are as complete as possible.

$\mathrm{CC}_{\mathrm{R}}$ alignment for sequence comparison was performed by ClustalW with Lasergene 8.0 MegAlign software (DNASTAR, Inc., Madison, WI, U.S.A.) on default settings. All alignments for phylogenetic analysis were performed in MEGA 4.0 (Tamura et al. 2007) using ClustalW on default settings. Phylogenies were constructed by the neighbor-joining method (Saitou and Nei 1987) using the PAM matrix (Schwartz and Dayhoff 1979), and all trees shown are bootstrap consensus trees derived from 1,000 replicates.

\section{Cloning and plasmid construction.}

All new constructs used for protein expression were created by inserting the sequence of interest into the $\mathrm{Xba \textrm {I }}$ and $\mathrm{BamHI}$ sites of the pBIN61 binary vector with a C-terminal hemagglutinin (HA) tag (Bendahmane et al. 2002). I2, R3a, and RB CC domains were cloned by reverse-transcriptase polymerase chain reaction (RT-PCR) from tomato (I2) and potato (R3a and $\mathrm{RB}) \mathrm{cDNA}$. An ADR1 homolog was identified on potato BAC RH134N13 (GenBank accession AC233501.1) by BLAST search of genomic sequence available from the SOL Genomics Network (SGN) (Mueller et al. 2005), and was used for primer design. Full-length StADR1 was cloned from potato 'Eva' cDNA (GenBank accession HQ906887) and served as template for construction of StADR1 $C_{R}$. Full-length and truncated NRG1 variants were cloned from 35S-NRG1 (Peart et al. 2005). $\mathrm{CC}_{\mathrm{R}}$ domains of Arabidopsis ADR1 (amino acids 1 to 146), ADR1-L1 (1 to 155), ADR1-L2 (1 to 153), NRG1.1 (1 to 149), and NRG1.2 (1 to 151) were cloned from A. thaliana ecotype Columbia by RT-PCR. Cloning of Rx and Bs2 CC domains (Moffett et al. 2002), Rx NB:eGFP (Rairdan et al. 2008), Rx D460V (Bendahmane et al. 2002), PVX:GFP (Peart et al. 2002a), and 35S:Bax (del Pozo et al. 2004) have been previously described.

To construct pTV:NRG1, a 493-bp fragment of NRG1 from a position similar to that in the previously described TRV:NRG1 clone (Peart et al. 2005) was cloned from N. benthamiana cDNA and inserted into the EcoRI and XhoI sites of the pGIITV vector (Ratcliff et al. 2001). pTV:ADR1 consists of a 543-bp fragment of ADR1 cloned from $N$. tabacum inserted into the XmaI and XhoI sites of pGIITV. Nicotiana ADR1 primers were designed based on processed tobacco genome sequence c14852 identified through SGN. pTV:NRG1/ADR1 consists of the aforementioned NRG1 and ADR1 fragments, separated by an XhoI site, inserted into the XmaI and EcoRI 
sites of pGIITV. TV:SGT1 (Peart et al. 2002b) and TV:00 (Ratcliff et al. 2001) have been previously described.

Nucleotide sequences of all primers used in this study are listed in Supplementary Table S2. RNA was extracted using TRIzol reagent (Invitrogen, San Diego, CA, U.S.A.) and cDNA first-strand synthesis was performed using SuperScript III reverse transcriptase (Invitrogen). PCR was performed with KOD high-fidelity polymerase (Novagen, Madison, WI, U.S.A.). All new constructs were sequence verified.

\section{Transient expression and protein analysis.}

All binary vectors for protein expression were transformed into Agrobacterium tumefaciens $\mathrm{C} 58 \mathrm{C} 1$, carrying virulence plasmid $\mathrm{pCH} 32$. Agroinfiltrations were performed as previously described (Bendahmane et al. 2002) at optical density at $600 \mathrm{~nm}\left(\mathrm{OD}_{600}\right)=0.2$. For PVX:GFP co-expression, Agrobacterium tumefaciens GV3101 carrying the PVX:GFP-expressing binary vector pGR208, along with virulence plasmid pSoup (Peart et al. 2002b), was agroinfiltrated at $\mathrm{OD}_{600}=$ 0.001 . Protein analysis by immunoblotting was performed as previously described (Bhattacharjee et al. 2009), with the exception that HA-tagged proteins were ground in Laemmli buffer (Laemmli 1970). PVX CP was visualized as previously described (Bhattacharjee et al. 2009) and HA epitope tagged proteins were visualized using a monocolonal anti HA-peroxidase antibody (Sigma). Protein quantification by image analysis was performed using ImageJ (Abramoff et al. 2004), with images converted to an 8-bit grayscale.

\section{VIGS.}

Three leaves each of 3-week-old Rx2 transgenic $N$. benthamiana (Bhattacharjee et al. 2009) seedlings were co-infiltrated with Agrobacterium strains carrying plasmids pBINTra6 (TRV RNA1 cDNA) and RNA2 constructs derived from pTV:00 (Ratcliff et al. 2001) at concentrations of $\mathrm{OD}_{600}=0.1$ and 0.2 , respectively. Three weeks later, three to five leaves per plants were dusted with Carborundum powder and rub inoculated with sap containing PVX:GFP virions, prepared as previously described (Bhattacharjee et al. 2009). Systemic tissue was monitored for necrosis for up to 50 days following PVX:GFP inoculation. TV:00, TV:ADR1, and TV:NRG1/ADR1 results were each derived from 26 individuals distributed over three replicates, and TV:NRG1 results were derived from 21 individuals distributed over four replicates.

\section{ACKNOWLEDGMENTS}

This work was supported by funding from the National Science Foundation (IOB-0343327) and the National Science and Engineering Council (Canada) to P. Moffett, a postdoctoral fellowship from the Fonds Quebecois de la Recherche sur la Nature et les Technologies to L.-P. Hamel, and a National Science Foundation graduate research fellowship to S. M. Collier. We thank S. Xiao, R. Berkey, and J. Vega-Arreguin for critical review of this manuscript; P. Mestre, D. Klessig, and P. Manosalva for insightful discussions and suggestions; and D. Baulcombe for NRG1 clones.

\section{LITERATURE CITED}

Abramoff, M. D., Magelhaes, P. J., and Ram, S. J. 2004. Image processing with ImageJ. Biophotonics Int. 11:36-42.

Argout, X., Salse, J., Aury, J.-M., Guiltinan, M.J., Droc, G., Gouzy, J., Allegre, M., Chaparro, C., Legavre, T., Maximova, S. N., Abrouk, M., Murat, F., Fouet, O., Poulain, J., Ruiz, M., Roguet, Y., Rodier-Goud, M., Barbosa-Neto, J. F., Sabot, F., Kudrna, D., Ammiraju, J. S. S., Schuster, S. C., Carlson, J. E., Sallet, E., Schiex, T., Dievart, A., Kramer, M., Gelley, L., Shi, Z., Bérart, A., Viot, C., Boccara, M., Risterucci, A. M., Guignon, V., Sabau, X., Axtell, M. J., Ma, Z., Zhang, Y., Brown, S., Bourge, M., Golser, W., Song, X., Clement, D., Rivallan, R., Tahi, M., Akaza, J. M., Pitollat, B., Gramacho, K., D'Hont, A., Brunel, D., Infante, D., Kebe, I.,
Costet, P., Wing, R., McCombie, W. R., Guiderdoni, E., Quetier, F., Panaud, O., Wincker, P., Bocs, S., and Lanaud, C. 2011. The genome of Theobroma cacao. Nat. Genet. 43:101-108.

Bai, J., Pennill, L. A., Ning, J., Lee, S. W., Ramalingam, J., Webb, C. A., Zhao, B., Sun, Q., Nelson, J. C., Leach, J. E., and Hulbert, S. H. 2002. Diversity in nucleotide binding site-leucine-rich repeat genes in cereals. Genome Res. 12:1871-1884.

Bakker, E. G., Toomajian, C., Kreitman, M., and Bergelson, J. 2006. A genome-wide survey of $R$ gene polymorphisms in Arabidopsis. Plant Cell 18:1803-1818.

Bendahmane, A., Querci, M., Kanyuka, K., and Baulcombe, D. C. 2000. Agrobacterium transient expression system as a tool for the isolation of disease resistance genes: Application to the Rx2 locus in potato. Plant $\mathrm{J}$. 21:73-81.

Bendahmane, A., Farnham, G., Moffett, P., and Baulcombe, D. C. 2002. Constitutive gain-of-function mutants in a nucleotide binding site-leucine rich repeat protein encoded at the Rx locus of potato. Plant $\mathrm{J}$. 32:195-204.

Bhattacharjee, S., Zamora, A., Azhar, M. T., Sacco, M. A., Lambert, L. H., and Moffett, P. 2009. Virus resistance induced by NB-LRR proteins involves Argonaute4-dependent translational control. Plant J. 58:940-951.

Bieri, S., Mauch, S., Shen, Q. H., Peart, J., Devoto, A., Casais, C., Ceron, F., Schulze, S., Steinbiss, H. H., Shirasu, K., and Schulze-Lefert, P. 2004. RAR1 positively controls steady state levels of barley MLA resistance proteins and enables sufficient MLA6 accumulation for effective resistance. Plant Cell 16:3480-3495.

Cannon, S. B., Zhu, H., Baumgarten, A. M., Spangler, R., May, G., Cook, D. R., and Young, N. D. 2002. Diversity, distribution, and ancient taxonomic relationships within the TIR and non-TIR NBS-LRR resistance gene subfamilies. J. Mol. Evol. 54:548-562.

Chase, M. W., and Reveal, J. L. 2009. A phylogenetic classification of the land plants to accompany APG III. Bot. J. Linn. Soc. 161:122-127.

Chini, A., and Loake, G. J. 2005. Motifs specific for the ADR1 NBS-LRR protein family in Arabidopsis are conserved among NBS-LRR sequences from both dicotyledonous and monocotyledonous plants. Planta 221:597601.

Chini, A., Grant, J. J., Seki, M., Shinozaki, K., and Loake, G. J. 2004. Drought tolerance established by enhanced expression of the $C C-N B S$ $L R R$ gene, $A D R 1$, requires salicylic acid, EDS1, and ABI1. Plant J. 38:810-822.

Chisholm, S. T., Coaker, G., Day, B., and Staskawicz, B. J. 2006. Host-microbe interactions: Shaping the evolution of the plant immune response. Cell 124:803-814.

Collier, S. M., and Moffett, P. 2009. NB-LRRs work a "bait and switch" on pathogens. Trends Plant Sci. 14:521-529.

del Pozo, O., Pedley, K. F., and Martin, G. B. 2004. MAPKKK $\alpha$ is a positive regulator of cell death associated with both plant immunity and disease. EMBO (Eur. Mol. Biol. Soc.) J. 23:3072-82.

Flor, H. H. 1971. Current status of the gene-for-gene concept. Annu. Rev. Phytopathol. 9:275-296.

Frost, D., Way, H., Howles, P., Luck, J., Manners, J., Hardham, A., Finnegan, J., and Ellis, J. 2004. Tobacco transgenic for the flax rust resistance gene $L$ expresses allele-specific activation of defense responses. Mol. Plant-Microbe Interact. 17:224-232.

Grant, J. J., Chini, A., Basu, D., and Loake, G. J. 2003. Targeted activation tagging of the Arabidopsis NBS-LRR gene, ADR1, conveys resistance to virulent pathogens. Mol. Plant-Microbe Interact. 16:669-680.

Jermstad, K. D., Sheppard, L. A., Kinloch, B. B., Delfina-Mix, A., Ersoz, E. S., Krutovsky, K. V., and Neale, D. B. 2006. Isolation of a full-length CC-NBS-LRR resistance gene analog candidate from sugar pine showing low nucleotide diversity. Tree Genet. Genomics 2:76-85.

Jones, J. D., and Dangl, J. L. 2006. The plant immune system. Nature 444:323-329.

Kadota, Y., Shirasu, K., and Guerois, R. 2010. NLR sensors meet at the SGT1-HSP90 crossroad. Trends Biochem. Sci. 35:199-207.

Krasileva, K. V., Dahlbeck, D., and Staskawicz, B. J. 2010. Activation of an Arabidopsis resistance protein is specified by the in planta association of its leucine-rich repeat domain with the cognate oomycete effector. Plant Cell 22:2444-2458.

Laemmli, U. K. 1970. Cleavage of structural proteins during the assembly of the head of bacteriophate T4. Nature 227:680-695.

Leipe, D. D., Koonin, E. V., and Aravind, L. 2004. STAND, a class of Ploop NTPases including animal and plant regulators of programmed cell death: Multiple, complex domain architectures, unusual phyletic patterns, and evolution by horizontal gene transfer. J. Mol. Biol. 343:1-28.

Leister, R. T., Dahlbeck, D., Day, B., Li, Y., Chesnokova, O., and Staskawicz, B. J. 2005. Molecular genetic evidence for the role of SGT1 in the intramolecular complementation of Bs 2 protein activity in Nico- 
tiana benthamiana. Plant Cell 17:1268-1278.

Lupas, A., Van Dyke, M., and Stock, J. 1991. Predicting coiled coils from protein sequences. Science 252:1162-1164.

McDowell, J. M., and Simon, S. A. 2006. Recent insights into $R$ gene evolution. Mol. Plant Pathol. 7:437-448.

McHale, L., Tan, X., Koehl, P., and Michelmore, R. W. 2006. Plant NBSLRR proteins: Adaptable guards. Genome Biol. 7:212.

Meyers, B. C., Dickerman, A. W., Michelmore, R. W., Sivaramakrishnan, S., Sobral, B. W., and Young, N. D. 1999. Plant disease resistance genes encode members of an ancient and diverse protein family within the nucleotide-binding superfamily. Plant J. 20:317-332.

Meyers, B. C., Kozik, A., Griego, A., Kuang, H., and Michelmore, R. W. 2003. Genome-wide analysis of NBS-LRR-encoding genes in Arabidopsis. Plant Cell 15:809-834.

Moffett, P., Farnham, G., Peart, J., and Baulcombe, D. C. 2002. Interaction between domains of a plant NBS-LRR protein in disease resistancerelated cell death. EMBO (Eur. Mol. Biol. Soc.) J. 21:4511-4519.

Mueller, L. A., Solow, T. H., Nicolas, T., Skwarecki, B., Buels, R., Binns, J., Lin, C., Wright, M. H., Aherns, R., Wang, Y., Herbst, E. V., Keyder, E. R., Menda, N., Zamir, D., and Tanksley, S. D. 2005. The SOL genomics network: A comparative resource for Solanaceae biology and beyond. Plant Physiol. 138:1310-1317.

Pan, Q., Wendel, J., and Fluhr, R. 2000. Divergent evolution of plant NBSLRR resistance gene homologues in dicot and cereal genomes. J. Mol. Evol. 50:203-213.

Peart, J. R., Cook, G., Feys, B. J., Parker, J. E., and Baulcombe, D. C. 2002a. An EDS1 orthologue is required for N-mediated resistance against Tobacco mosaic virus. Plant J. 29:569-79.

Peart, J. R., Lu, R., Sadanandom, A., Malcuit, I., Moffett, P., Brice, D. C., Schauser, L., Jaggard, D. A., Xiao, S., Coleman, M. J., Dow, M., Jones, J. D., Shirasu, K., and Baulcombe, D. C. 2002b. Ubiquitin ligase-associated protein SGT1 is required for host and nonhost disease resistance in plants. Proc. Natl. Acad. Sci. U.S.A. 99:10865-10869.

Peart, J. R., Mestre, P., Lu, R., Malcuit, I., and Baulcombe, D. C. 2005. NRG1, a CC-NB-LRR protein, together with N, a TIR-NB-LRR protein, mediates resistance against Tobacco mosaic virus. Curr. Biol. 15:968-973.

Rairdan, G. J., Collier, S. M., Sacco, M. A., Baldwin, T. T., Boettrich, T., and Moffett, P. 2008. Novel roles for the CC and NB domains in signaling and recognition by the Rx NB-LRR disease resistance protein. Plant Cell 20:739-751.

Ratcliff, F., Martin-Hernandez, A. M., and Baulcombe, D. C. 2001. Tobacco rattle virus as a vector for analysis of gene function by silencing. Plant J. 25:237-245.

Rentel, M. C., Leonelli, L., Dahlbeck, D., Zhao, B., and Staskawicz, B. J. 2008. Recognition of the Hyaloperonospora parasitica effector ATR13 triggeres resistance against oomycete, bacterial, and viral pathogens. Proc. Natl. Acad. Sci. U.S.A. 105:1091-1096.

Sacco, M. A., and Moffett, P. 2009. Disease resistance genes: Form and function. Pages 94-141 in: Molecular Plant-Microbe Interactions. K. Bouarab, N. Brisson, and F. Daayf, eds. CABI, Wallingford, U.K.

Sacco, M. A., Mansoor, S., and Moffett, P. 2007. A RanGAP protein physically interacts with the NB-LRR protein $\mathrm{Rx}$, and is required for Rx-mediated viral resistance. Plant J. 52:82-93

Saitou, N., and Nei, M. 1987. The neighbor-joining method: A new method for reconstructing phylogenetic trees. Mol. Biol. Evol. 4:406-425.

Sakai, H., and Itoh, T. 2010. Massive gene losses in Asian cultivated rice unveiled by comparative genome analysis. BMC Genomics 11:121.

Schwartz, R. M., and Dayhoff, M. O. 1979. Matrices for detecting distant relationships. Pages 353-358 in: Atlas of protein sequences and structure, Vol. 5. Dayhoff, M. O. ed. National Biomedical Research Foundation, Washington, D.C.

Sohn, K. H., Lei, R., Nemri, A., and Jones, J. 2007. The downy mildew effector proteins ATR1 and ATR13 promote disease susceptibility in Arabidopsis thaliana. Plant Cell 19:4077-4090.
Swiderski, M. R., Birker, D., and Jones, J. D. 2009. The TIR domain of the TIR-NB-LRR resistance protein is a signaling domain involved in cell death induction. Mol. Plant-Microbe Interact. 22:157-165.

Tameling, W. I., Elzinga, S. D., Darmin, P. S., Vossen, J. H., Takken, F. L., Haring, M. A., and Cornelissen, B. J. 2002. The tomato R gene products I-2 and MI-1 are functional ATP binding proteins with ATPase activity. Plant Cell 14:2929-2939.

Tamura, K., Dudley, J., Nei, M., and Kumar, S. 2007. MEGA4: Molecular Evolutionary Genetics Analysis (MEGA) software version 4.0. Mol. Biol. Evol. 24:1596-1599.

Tarr, D. E. K., and Alexander, H. M. 2009. TIR-NBS-LRR genes are rare in monocots: Evidence from diverse monocot orders. BMC Res. Notes $2: 197$.

Tobias, C. M., Oldroyd, G. E., Chang, J. H., and Staskawicz, B. J. 1999. Plants expressing the Pto disease resistance gene confer resistance to recombinant PVX containing the avirulence gene AvrPto. Plant J. 17:41-50

Tschopp, J. T., and Schroder, K. 2010. NLRP3 inflammasome activation: The convergence of multiple signalling pathways on ROS production? Nat. Rev. Immunol. 10:210-215.

Velasco, R., Zharkikh, A., Affourtit, J., Dhingra, A., Cestaro, A., Kalyanaraman, A., Fontanta, P., Bhatnagar, S. K., Troggio, M., Pruss, D., Salvi, S., Pindo, M., Baldi, P., Castelletti, S., Cavaiuolo, M., Coppola, G., Costa, F., Cova, V., Dal Ri, A., Goremykin, V., Komjanc, M., Longhi, S., Magnago, P., Malacarne, G., Malnoy, M., Micheletti, D., Moretto, M., Perazzolli, M., Si-Ammour, A., Vezzulli, S., Zini, E., Eldredge, G., Fitzgerald, L. M., Gutin, N., Lanchbury, J., Macalma, T., Mitchell, J. T., Reid, J., Wardell, B., Kodira, C., Chen, Z., Desany, B., Niazi, F., Palmer, M., Koepke, T., Hiwan, D., Schaeffer, S., Krishnan, V., Wu, C., Chu, V. T., King, S. T., Vick, J., Tao, Q., Mraz, A., Stormo, A., Stormo, K., Bogden, R., Ederle, D., Stella, A., Vecchietti, A., Kater, M. M., Masiero, S., Lasserre, P., Lespinasse, Y., Allan, A. C., Bus, V., Chagné, D., Crowhurst, R. N., Cleave, A. P., Lavezzo, E., Fawcett, J. A., Proost, S., Rouzé, P., Sterck, L., Toppo, S., Lazzari, B., Hellens, R. P., Durel, C-E., Gutin, A., Bumgarner, R. E., Gardiner, S. E., Skolnick, M., Egholm, M., de Peer, Y. V., Salamini, F., and Viola, R. 2010. The genome of the domesticated apple (Malus $\times$ domestica Borkh.). Nat. Genet. 41:833-841.

Wang, W., Wen, Y., Berkey, R., and Xiao, S. 2009. Specific targeting of the Arabidopsis resistance protein RPW8.2 to the interfacial membrane encasing the fungal haustorium renders broad-spectrum resistance to powdery mildew. Plant Cell 21:2898-2913.

Xiao, S., Ellwood, S., Calis, O., Patrick, E., Li, T., Coleman, M., and Turner, J. G. 2001. Broad-spectrum mildew resistance in Arabidopsis thaliana mediated by RPW8. Science 291:118-120.

Xiao, S., Emerson, B., Ratanasut, K., Patrick, E., O'Neill, C., Bancroft, I., and Turner, J. G. 2004. Origin and maintenance of a broad-spectrum disease resistance locus in Arabidopsis. Mol. Biol. Evol. 21:1661-1672.

$\mathrm{Xu}$, Q., Biswas, M. K., Lan, H., Zeng, W., Liu, C., Xu, J., and Deng, X. 2011. Phylogenetic and evolutionary analysis of NBS-encoding genes in Rutaceae fruit crops. Mol. Genet. Genomics 285:151-161.

Zhang, M., Botör, M., Li, K., Kadota, Y., Panaretou, B., Prodromou, C., Shirasu, K., and Pearl, L. H. 2008. Structural and functional coupling of Hsp90- and Sgt1-centered multi-protein complexes. EMBO (Eur. Mol. Biol. Soc.) J. 27:2789-2798.

\section{AUTHOR-RECOMMENDED INTERNET RESOURCES}

COILS software: www.ch.embnet.org/software/COILS form.html

National Center for Biotechnology Information database: www.ncbi.nlm.nih.gov

Pfam database: pfam.sanger.ac.uk

Phytozome database: www.phytozome.net

Sol Genomics Network website: solgenomics.net 